\title{
LA RELEVANCIA DE LA PRODUCGIÓN EDITORIAL BUDISTA EN LA VISIBILIZACIÓN DEL BUDISMO EN ESPAÑA
}

\author{
THE RELEVANCE OF BUDDHIST EDITORIAL \\ PRODUCTION IN THE VISIBILITY OF BUDDHISM \\ IN SPAIN
}

Francisco DieZ DE VeLASCO

Universidad de La Laguna*

\begin{abstract}
ResUMEN: El presente trabajo repasa la producción editorial budista española, que resulta muy destacada, cercana a los dos millares de libros. El artículo tiene dos partes principales. En la que se titula «Las estrategias de publicación de los grupos budistas: las editoriales generalistas» se analizan las obras de autores budistas publicadas en editoriales no especializadas, entre las que destaca Kairós, con más de un centenar de títulos. En el siguiente apartado se repasan las editoriales de orientación budista evidenciando la importancia de las que se asocian con grupos del budismo tibetano entre las que destaca Ediciones Dharma. Esta producción de libros resulta un elemento notable en la visibilización del budismo en España que lleva a que tras el cristianismo sea la religión con mayor presencia editorial en el país.

\footnotetext{
* Catedrático de Universidad. Instituto de Ciencias Políticas y Sociales. Universidad de La Laguna (Canarias). Email: fradive@ull.edu.es; ORCID: 0000-0002-9913-4580. Este trabajo se inserta en el Proyecto de investigación Bases teóricas y metodológicas para el estudio de la diversidad religiosa y las minorias religiosas en España (HAR2016-75173-P) del MINECO/ MICINN, 2017-2020 y en el programa María Rosa Alonso de ayudas a la investigación en Humanidades y Ciencias Sociales del Cabildo de Tenerife (2018-2019). Utiliza materiales generados como resultado del contrato de investigación «Budismo en España» entre la Fundación Pluralismo y Convivencia (Madrid, España) y la Universidad de La Laguna. Este artículo pone al día y desarrolla de modo sistemático algunos argumentos y planteamientos expuestos en Díez de Velasco, 2013: 98-108 y 2018: 77-83.
} 
Palabras clave: Budismo, editoriales, España, visibilización religiosa.

Aвstract: This paper reviews Spanish Buddhist editorial production, which is quite outstanding, comprising nearly two thousand books. The work has two main parts. In the part titled «Publishing strategies of Buddhist groups: generalist publishers», the works of Buddhist authors published in non-specialized publishers are analyzed; among these, Editorial Kairós stands out, with more than a hundred titles. In the following section, the Buddhist-oriented publishing houses are reviewed, demonstrating the importance of the publishers that are associated with groups of Tibetan Buddhism, among which Ediciones Dharma stands out. This outstanding production of books is a remarkable element in the visibility of Buddhism in Spain, leading Buddhism to be the religion with the greatest presence in publishing in the country, after Christianity.

KeYwords: Buddhism, publishing houses, Spain, religious visibilization.

\section{Introducción}

En el campo religioso español, el budismo ${ }^{1}$ no destaca particularmente por el volumen de sus seguidores, que se estiman entre 80.000 y 200.000, un número muy inferior al de católicos, no religiosos-ateos, evangélicos, musulmanes o cristianos ortodoxos, y cercano o algo superior al de Testigos de Jehová, mormones o hinduistas. Tampoco presenta un estatus jurídico de máximo privilegio, que caracteriza a las confesiones que tienen firmados acuerdos con el Estado (en primer lugar católicos, y desde 1992 judíos, musulmanes y evangélicos), aunque sí goza de un estatus de cierta relevancia puesto que desde 2007 ha sido reconocido como confesión de notorio arraigo aunque sin acuerdos (con anterioridad habían alcanzado dicho reconocimiento mormones y Testigos de Jehová y con posterioridad los cristianos ortodoxos). Presenta un patrimonio monumental

\footnotetext{
1 Para esta aproximación a la visibilización numérica, jurídica y patrimonial del budismo en Espańa, que se expone en la introducción utilizamos tanto la explotación de datos del Observatorio del Pluralismo Religioso en España (http://www.observatorioreligion.es/directoriolugares-de-culto) como los trabajos de Díez de Velasco (2013: 85ss.; 2012: 7ss.), los grupos budistas españoles citados en este artículo son tratados con detalle en el capítulo V de Díez de Velasco (2013: 189-296; 2018: 163-262).
} 
que supera los 160 lugares de práctica registrados, es decir, menos que católicos (que multiplican por 200 dicha cifra), evangélicos (con más de 4.000 centros), musulmanes (con 10 veces más centros que los budistas), Testigos de Jehová (que cuadruplican a los budistas), ortodoxos (con más de 200 centros), aunque superando a los mormones (con 120 centros) y evidenciándose, y resulta un asunto relevante, que algunos monumentos budistas muy notables jalonan la geografía española, por ejemplo, el estupa de Benalmádena - uno de los mayores fuera de Asia - o monasterios impresionantes como Dag Shang Kagyu en Panillo (Huesca), Osel Ling (Bubión, Granada) o Karma Guen (Vélez-Málaga), entre los que tienen más solera.

Pero en lo que destaca muy significativamente el budismo en España es en la producción editorial, que supera los dos millares de títulos en la última media centuria y que convierte al budismo, después del cristianismo, en la religión mejor representada como producto editorial en España, por delante incluso del judaísmo y del islam, el hinduismo y otras religiones con mayor visibilización numérica, jurídica o patrimonial en nuestro país y a escala mundial. Se trata por tanto de un elemento notable a la hora de evidenciar la visibilización patrimonial de esta religión en nuestro país, y será está la finalidad principal del artículo. Pero desde luego hay que contextualizar este dato numérico, que pudiera parecer muy destacado, pues hay que tener en cuenta que el español es una de las lenguas vehiculares de cultura más importantes del mundo en la actualidad, y la producción bibliográfica en nuestra lengua es de las más voluminosas y el mercado iberoamericano uno de los que un mayor desarrollo potencial presenta. Pero que el budismo tenga una presencia tal en las editoriales españolas (y no trataremos en estas líneas las de otros países hispanohablantes, algunos con una producción muy notable, en especial Argentina y México) evidencia que se trata de un producto de éxito que no desentona en la línea de la aprobación social (el contra-estigma) que presenta el budismo tanto en el mundo occidental en general como en el español en particular (analizado con más argumentos en Díez de Velasco 2013; 2018).

Hay que tener en cuenta que el budismo como producto editorial ha estado presente en España desde finales del siglo XIX (Webb, 1998: 371ss.), desde la tesis pionera de Francisco García Ayuso (1885). Pero a partir de los años 80 del siglo XX los libros budistas editados en nuestro país se han multiplicado y en la actualidad es difícil encontrar una editorial de cierta relevancia que no incluya algún título de budismo en su catálogo, tanto traducciones como obras de autores españoles. En el elenco de estos últimos hay que otorgar un lugar de 
relevancia justamente a María Teresa Román, a quien se dedica este homenaje, puesto que el budismo fue uno de sus temas predilectos y al que dedicó, además de diversos artículos y múltiples materiales audiovisuales, tres libros completos (Román, 1997; 2002; 2007; también 2004), e incluso su tesis doctoral (Román, 1994). Pero revisar la totalidad de la producción editorial española sobre budismo es un tema que excedería los límites de un artículo y exigiría una monografía, por tanto en las páginas siguientes solamente nos centraremos en la producción editorial generada por autores budistas y en especial se repasarán las editoriales que presentan una clara orientación budista. La producción académica y erudita sobre budismo editada en España, que es donde se insertaría la obra de María Teresa Román, no se revisará más que de modo no sistemático, aunque se tendrá en cuenta en los casos en que ambos mundos se mezclan y el perfil del erudito académico y universitario se entrelaza con el del practicante y resulta paradigmática la trayectoria del profesor Robert Thurman, con una variada producción traducida al español donde los temas académicos se combinan con los de índole que se podría denominar como más confesional (Thurman, 1994; 1995; 2000; 2006; 2012; 2014).

\section{Las estrategias de publicación de los grupos budistas: las editoriales generalistas}

Los grupos budistas españoles, que suelen centrarse tanto en la meditación como en el estudio, han tendido a necesitar, producir y utilizar mucho material escrito. Era común que confeccionasen de modo artesanal folletos y otros diversos documentos para compartirlos con los miembros e interesados. En algunos casos llegaban a tener decenas de pequeñas publicaciones propias con millares de páginas elaboradas. Pero algunos grupos, generalmente los más activos y con un mayor número de seguidores, dieron el paso de profesionalizar algunas de sus publicaciones optando por poner en marcha editoriales budistas. Se trata de una estrategia exigente, puesto que requiere esfuerzos tanto logísticos como económicos a los grupos que apuestan por ella, pero es la que mayor éxito alcanza en la socialización a gran escala de los materiales que generan o les interesa divulgar, llegando también a poder abrir el espectro de publicaciones a autores budistas más generales, cuando la editorial alcanza una cierta talla, como ha ocurrido en alguna de ellas, y en particular con la editorial Dharma. 
Pero hay que contextualizar esa opción, que ha resultado minoritaria en el conjunto de los centenares de grupos budistas que hay en Espańa, ya que la estrategia más común ha sido apostar simplemente por la producción interna de materiales sobre la que, además, ha incidido el gran cambio tecnológico de internet que lleva a que actualmente suelan ubicar estos grupos sus textos y otros documentos y materiales, muchos de ellos audiovisuales, en sus páginas web, compartirlos en listas de correo, repositorios y otros instrumentos que ofrece el ciberespacio y que no requieren la más costosa inversión de esfuerzos de preparación de manuscritos y de logística que implica querer acceder al mercado editorial estándar.

Y finalmente también hay que destacar una tercera estrategia, un camino mixto consistente en, además de poder optar por el recurso a la producción propia para algunos materiales de uso interno, apostar por confeccionar o traducir materiales más elaborados en forma de libros y situarlos en el mercado editorial general. Y también algunos grupos han tendido a promover o sugerir la traducción y publicación de libros budistas que les interesaban de entre la enorme cantidad de ellos que hay a disposición, tanto obras de maestros clásicos como de autores actuales, puesto que hay que destacar que el budismo podría denominarse, más que "una religión del libro» una "religión de la biblioteca» por lo extenso del patrimonio escrito que ha generado y genera. Esta labor de promoción por parte de los grupos budistas espańoles o por algunos miembros de estos ha sido uno de los detonantes de la multiplicación de libros budistas, generados desde las necesidades de los grupos. Pero si bien de este modo han alcanzado una difusión mayor, además han evidenciado, por el éxito de ventas, que el budismo era y es un producto rentable, lo que ha llevado a muchas editoriales generalistas a no desdeñar apostar por este tipo de propuestas en sus catálogos. La diferencia con la estrategia que revisaremos en el apartado siguiente es que estos libros no se canalizan por medio de editoriales promovidas por los propios grupos, sino que se ofrecen a editoriales de ámbito general, aunque muchas de ellas se elijan por una especial sensibilidad hacia los temas orientales o por tener incluso una línea de publicación de obras budistas, resultando notable que algunas de ellas sean editoriales católicas, asunto notable por lo contraintuitivo que pudiera parecer (que editoriales confesionales católicas incluyan en sus catálogos un cierto número de obras de otra opción religiosa).

Centrándonos en esta estrategia de publicar en editoriales de ámbito general, comenzaremos evidenciando un caso ejemplar, que merece revisarse con algún detalle, y que ofrece Dokushô Villalba (Francisco Fernández Villalba). Ha sido 
el fundador de uno de los grupos zen españoles con más trayectoria, con un templo en la provincia de Valencia y una decena de centros en toda España: la Comunidad Budista Soto Zen (CBSZ). Villalba es uno de los más antiguos practicantes españoles del zen (desde 1977), reconocido, además, como maestro zen en Japón en 1987, siendo el primer español en llegar a ello (Alongina, 1998). Comenzó desarrollando una temprana labor de traducción desde el francés al español de muchos libros y de comentarios de textos clásicos (en especial de Dogen) que había publicado su maestro Taisen Deshimaru (1980; 1981a-b; 1982a-c; 1987a-b, 1988; también 1991) y dos de las cuales han sido vertidas al catalán por las ediciones de la Abadía de Montserrat (Deshimaru, 2003; 2010), uno de los centros señeros del catolicismo catalán ${ }^{2}$. Estas traducciones de Villalba aparecieron en editoriales con una proyección orientalista notable, como Kairós o Miraguano, que se repasarán más adelante, o Luis Cárcamo, y en un caso hasta promovió una coedición (Deshimaru, 1986), publicada por Las mil y una ediciones y la Asociación zen de España que es como se llamaba el grupo que lideraba Villalba en ese entonces, además de publicaciones desde el grupo que lidera en la actualidad, autoeditando como Comunidad Budista Soto Zen, por ejemplo, una obra de Kodo Sawaki (2012), el maestro de Deshimaru. También ha traducido a clásicos del zen destacando, en especial muchas obras de Dogen, editadas y comentadas por él mismo (Dogen, 1987; 1989; 2011; 2012; 2015ab) o de Hui-Neng (1985), así como antologías de maestros zen (por ejemplo, Villalba, 2010) o hasta un libro del actual Dalai Lama (1982a), para Luis Cárcamo editor, una casa editorial de clara dedicación a los temas esotéricos, entre los que el budismo tibetano o el zen no desentonaban en aquella época. Además de traductor, destaca su labor como autor de libros sobre budismo zen, publicados muy mayoritariamente en la editorial Miraguano (Villalba, 1984; 1995; 1998; 1999; 2000; 2001; 2008; 2009), incluyendo también uno en edición propia de la CBSZ (Villalba 1997), así como materiales audiovisuales budistas en Cd y DVD (por ejemplo Villalba, 2005), para lo que crearon en la CBSZ una productora audiovisual, denominada Alalba. Hay que destacar en especial la labor de Villalba como director de dos colecciones en la editorial Miraguano especializadas en el zen. La más extensa, con más de una veintena de títulos, se llama Textos de la tradición zen, que incluye desde la temprana introducción al zen de este maestro español (Villalba, 1984, reeditada varias veces) a textos de maestros clásicos del zen y el chan como Dogen, Sosan, Seng-tsıan, Kakuan, Soseki, Huang-Po, y

2 Donde también se ha publicado a Nyanatiloka (1984) o la traducción del Dhammapada de Juan Mascaró (1982). Deshimaru ha sido muy traducido al catalán (Deshimaru, 1989; 2005, de hecho el primero salió en catalán antes que en castellano: Deshimaru, 1992). 
también sutras y otros textos traducidos tanto por Villalba, como en el pasado por Aigo Castro o más recientemente por Kepa Egiluz. También se incluyen en esta colección los tres volúmenes que forman los manuales de introducción al budismo que se utilizan en el programa de estudios budistas que desarrollan en la CBSZ y que han sido coordinados por el propio Dokushô Villalba, que se encargó de la redacción del último volumen, sobre el zen (Villalba, 2009), mientras que los dos anteriores son obras de Denkô Mesa (2005; 2007), antiguo maestro del grupo. La otra colección se llama De corazón a corazón, con una decena de obras y recoge enseñanzas del propio Villaba $(1998 ; 1999 ; 2000)$ y traducciones y ediciones, principalmente de Dogen (2001: 2007; 2010a; 2012; $2015 \mathrm{a})^{3}$. Villalba ha optado en varias ocasiones, incluso muy recientemente (es el caso de la nueva edición de 2016 de su Zen en la plaza del mercado, que obtuvo un gran impacto en su edición de 2008 por Aguilar) por la editorial Kairós. Se trata, dentro de las editoriales generalistas, de la que tiene un fondo de orientalismo y en especial de budismo más extenso y sistematizado (incluso publican catálogos especializados del tema), que roza el $20 \%$ de su producción y supera el centenar de títulos. ${ }^{4}$

\footnotetext{
3 Además de estas obras asociables con la CBSZ y con Villalba, se han publicado en Miraguano otros libros sobre el budismo fuera de estas dos colecciones, por ejemplo la reedición del célebre libro de Edwin Arnold (2008) o algunos sutras de los diálogos medios de Buda traducidos por Daniel de Palma (1998), además de los trabajos de José María Prieto (2011; también una edición de Dogen 2013) o de Ińaki Preciado (2013; 2015), del que en otras editoriales hay más trabajos tanto traducciones como obras propias (Preciado, 1994; 1998; 2000; 2001a-b; 2003; 2004, las dos últimas en ediciones Oberon).

4 Kairós comenzó a publicar libros de budismo incluso antes de la implantación de grupos budistas en nuestro país empezando con el célebre libro del monje trapense Thomas Merton sobre el zen (Merton, 1972; otros libros suyos en diferentes editoriales: 2000; 2004), seguido del de Herbert Guenther y Chögyam Trungpa sobre el tantra (Trungpa, 1976) y también de un libro poco habitual sobre el zen en Estados Unidos desde los ojos de un europeo escrito por Janwillem van de Wettering (1976, también interesa Wettering, 1984), autor más conocido por su éxito Afterzen (Wettering, 2000). Posteriormente han publicado de modo continuado obras de destacados maestros orientales como el actual Dalai Lama (2001c; 2002b; 2004f-g; 2007c; 2008c; 2009c; 2013b-c; 2014; 2015 y también Goleman, 1997), o el Karmapa Ogyen Trinle dorje (2017), Taisen Deshimaru (1979; 1990; 1994a; 2001a-b), Chögyam Trungpa (1986;1989; 1993; 1995; 1998a; 2002; 2007; 2010; 2016), Namkhai Norbu (1996; 2008; 2012; 2015; 2017), Yongey Mingyur Rimpoché (2016), Thich Nhat Hahn (1996a; 2000; 2011; 2013a-b; 2014a; 2017a), o de eruditos como Daisetz Teitaro Suzuki (1981; 1994; en otras editoriales: 1972; 1979a-b; 1996; 2001; 2006), Robert Thurman (1994; 2014) o autores occidentales como Alan Watts (1999; en otras editoriales: 1971; 1996), Albert Low (1994, con otras obras en ediciones Oberon: 2003 y Aura: 1977), Mariana Caplan, David Loy (2000; 2004; 2008; 2016), Mark Epstein, Joseph Goldstein (1996), Philip Kapleau (1981; en otras editoriales: 1994; 1999), Douglas Harding, Ken Wilber (2016, entre otros), con una cierta predilección por el zen, aunque se traten otras técnicas
} 
De la CBSZ han salido dos de sus miembros que fueron más activos y que han formado grupos propios y siguen una estrategia de publicación parecida a la de Villalba. Aigo Seiga Castro (Pedro Manuel Castro Sánchez) redactó en su día muchos materiales para la CBSZ y sus programas de estudio, pero dejó el grupo en 2000 y, tras su formación en Japón y su reconocimiento como maestro zen, fundó en 2006 el grupo denominado Tradición Budadharma del Zen Soto centrado en Valencia. Presenta la particularidad de haber cursado un máster en Estudios Budistas en la Universidad de Sunderland (Reino Unido), bajo la dirección del profesor Peter Harvey (Castro, 2011 fue su trabajo fin de máster), además de publicar (Castro, 2002) un trabajo sobre Dogen también en la editorial Kairós. Por su parte Denkô (Francisco) Mesa, que es el único de su comunidad al que Villalba otorgó la transmisión y reconoció como maestro en 2007, ha optado en 2016 por conformar un grupo propio, la Comunidad Budista Luz del Dharma y es autor, de forma independiente a los que publicó en Miraguano para el programa de estudios budista de la CBSZ, de varios libros sobre el zen (Mesa, 2009; 2013; 2016), que ha publicado en Shinden ediciones, que es una casa editorial especializada en obras sobre la cultura japonesa con especial foco en las artes marciales japonesas donde además de Mesa, sobre budismo en sentido estricto solo se cuenta con el trabajo de José Manuel Collado (2007), sobre el budismo esotérico japonés.

Uno de los centros zen más antiguos de nuestro país es el dojo Nalanda/ Centro zen Nalanda de Barcelona, que fundó el propio Deshimaru en su única visita a España, en 1981, lo coordina en la actualidad Josep Manuel So-sen Campillo que ha traducido y editado obras de Dogen (2010b; 2014) y de otros maestros clásicos del zen (Campillo, 2011a-b) y un libro propio sobre la meditación (Campillo, 2011c), publicados todos ellos en Olañeta, una editorial que

y orientaciones de meditación, incluida la vipasana y en los tiempos más recientes el mindfulness, destacando los trabajos del srilanqués Gunaratana (2012; 2013; 2015; 2016; 2017). También incluyen obras eruditas como la introducción de Donald Lopez (2009), el lúcido análisis de Bernard Faure (2012) o de Batchelor (2017) o trabajos de especialistas españoles como Juan Arnau (2007; en otras editoriales: 2004; 2006; 2011, donde muestra su capacidad en las traducciones) o excelentes traducciones directas de textos budistas como la de una selección de los Sermones Medios de Buda (Solé-Leris y Vélez, 1999), de Nagarjuna (Vélez, 2003, destacado budólogo español del que hay en Ediciones del Orto dos trabajos: Vélez, 1997; 2000) o de Vimalakirti (Ramírez, 2002) junto a libros más experienciales sobre los modos de vivir en budismo en lo cotidiano como el de Laia Montserrat $(2011$; 2017) o introducciones generales como la de Miguel Rodríguez de Peñaranda (2012). 
incluye una treintena de textos budistas de variadas orientaciones en su extenso catálogo de casi un millar y medio de obras 5 .

Otro ejemplo de colectivo dentro del zen que produce materiales propios pero también libros de divulgación general es el que lidera Bárbara Kosen (Richardeau), discípula de Deshimaru, que encabeza la Asociación Zen Taisen Deshimaru Zenkan y dirige un centro de prácticas de gran solera en Madrid (el Mokusan Dojo) y un templo (el Shorin-ji) en la provincia de Cáceres, además de media docena de otros grupos de prácticas. Es autora de dos libros en nuestra lengua (Kosen, 1999; 2002), uno en Mandala, editorial con un perfil de obras principalmente de autoayuda pero con un fondo de una veintena de libros sobre budismo ${ }^{6}$ y otro en la editorial Dilema, en la que es el único título de este tipo.

Entre los grupos españoles afiliados a la Asociación Zen Internacional, fundada por Deshimaru y liderada desde Francia, y que incluye una tupida red de más de una veintena de centros en España, destacan las traducciones de obras de líderes franceses con presencia esporádica en nuestro país como Yuno (Roland) Rech (2000; 2004; 2016), publicados en la editorial Milenio ${ }^{7}$, del abad del templo Seikyuji (La Morejona, Sevilla) Raphael Doko Triet, que vive temporadas en Espańa donde regenta una red de centros asociada al templo y que ha publicado en la editorial del propio grupo una recopilación de enseñanzas en entregas desde 2002 (Triet, 2002ss.) o también de líderes en nuestro país como Lluis Nansen Salas, que encabeza el dojo Kannon de Barcelona y que ha publicado tanto en la editorial del propio dojo materiales de uso más interno (Salas, 2016; 2017a) como una introducción más general a la meditación zen tanto en castellano (Salas, 2017c) en Ediciones Invisibles ${ }^{8}$ como en catalán (Salas, 2017b)

\footnotetext{
5 El editor José de Olañeta se ha dedicado a publicar desde 1983 principalmente textos de budismo tibetano y zen destacando media docena de obras del actual Dalai Lama (1997c; 1998a-b-c; 2001b; 2004d), una de Sogyal Rinpoché (1996b), también cuentos zen, una obra de Charlotte Joko Beck (1997; en la editorial Gaia: 2008; 2012) o los viajes de Alexandra David-Neel (2002).

6 Con varios trabajos de Dhiravamsa (que se revisarán más adelante), del famoso maestro zen y fotógrafo John Loori (2002), de Pedro San José (2009; 2010), Miguel Fraile (2006; 2008), Emilio Fiel (Miyo, 1993) o de Ana Crespo (1997 sobre el arte y el zen).

7 Donde se ha publicado también el libro de Evelyn de Smedt (1997) sobre Deshimaru o un interesante diálogo entre Francesc Torralba y Jamyang Wangmo (Helly Peláez Bozzi) (2002) de la que hay un libro publicado en Kailas (Wangmo, 2009).

8 Donde se ha publicado también a Ringu Tulku, que lidera el grupo internacional Bodhicharya, que ha publicado también una obra suya (Ringu, 2001) en la editorial del propio grupo y dos en catalán (Ringu, 2012; 2014).
} 
en la editorial Viena'. En todas estas editoriales los textos sobre budismo no son excepcionales.

También entre los grupos de orientación tibetana encontramos este tipo de estrategias. Uno de los más antiguos colectivos budistas españoles, que ha tomado la denominación de Samye Dzong y tiene su centro en Barcelona, presentando otros cuatro lugares de prácticas urbanas desde Madrid a Las Palmas y un monasterio en Cataluña llamado Samye Dechi Ling, es el que se configuró en torno a la figura del maestro tibetano Akong Rinpoché, cuya primera visita a España se realizó en 1977 y volvió en muchas otras ocasiones hasta su asesinato en 2013 en el Tíbet. Han producido muy numerosos materiales de factura propia autoeditados a lo largo de los años bajo el nombre del grupo o de la Fundación Rokpa, que revisaremos en el apartado siguiente, pero también han potenciado obras para un público extenso. Consisten en libros tanto del propio Akong (2006, en Ediciones i, y con anterioridad 1993 en la editorial budista española más destacada y que trataremos en el apartado siguiente, Dharma), del Karmapa (Trinle, 2013; 2017) en Kairós o Sirio ${ }^{10}$, y destaca también el libro de uno de los líderes locales del grupo, el lama Jinpa (Ángel Vidal Palet), implicado en las traducciones de las obras promovidas por el grupo, y que en este caso, al buscar un impacto más general, lo ha publicado en Ediciones i en castellano (Jinpa, 2006) y en Aeditors en catalán (Jinpa, 2011) y que es una guía muy bien construida sobre el imaginario tibetano del morir. La opción por Ediciones i resultó coherente puesto que entre 2005 y 2009 publicaba la revista Dharma, de clara inspiración budista, que se vendió en los quioscos y tuvo una distribución amplia y una periodicidad mantenida y entre sus autores budistas ha estado también el hermano de Akong Rimpoché, Yeshe Losal (2006), o el Tai Situ (2007), que hay que recordar que es uno de los grandes lamas del linaje kagyupa y que fue clave en el reconocimiento del XVII Karmapa al que el grupo sigue ${ }^{11}$.

\footnotetext{
9 Que está publicando hasta el presente una veintena de traducciones al catalán de obras de maestros budistas como el actual Dalai Lama, Ringu Tulku (2014), Ricard, Trungpa o Gunaratana algunas ya publicadas en castellano en Kairós o en otras editoriales.

10 Sirio tiene al actual Dalai Lama (1998e; 2001a), al XII Drukpa (2015), a la maestra Pema Chödron (2013a), Ramiro Calle (1994; 2009), Alan Watts (1996), Joseph Goldstein (2015) o Deshimaru (1995) en su catálogo.

11 Y que también ha publicado otra obra en la editorial Obelisco (Tai Situ, 1994), traducida por el propio lama Jinpa. En Ediciones i, además de los autores antes repasados relacionados con el linaje kagyupa se publicó también un libro del Dalai Lama (2007b) o el de Schneider (2007) dedicado al maestro zen Issan Dorsey.
} 
Otro maestro español que ha publicado algunas de sus obras para un público más general fuera de la que ha sido su comunidad, Dag Shang Kagyu, una de las redes más extensas del budismo español con su sede central en el monasterio homónimo sito en la provincia de Huesca y una docena de centros urbanos repartidos por toda Espańa y que regenta una editorial propia, Chabsel, que se repasará en el apartado siguiente, es el lama Djinpa-Borja de Arquer que ha optado por la Editora Librería Argentina (Djinpa, 2000; 2001; 2002). Se trata de una editorial con un fondo de orientalismo y de budismo destacable que alcanza el $10 \%$ de su catálogo ${ }^{12}$, donde también publica Saya Kunsal Kassapa-Joan Martínez Montsant (2011b; 2012) que lidera el colectivo Trikaya.

Juan Manzanera es otro maestro español con una larga trayectoria, que regenta en Madrid un centro enfocado en la meditación pero que ha publicado tanto obras propias como traducciones en la editorial budista Dharma (Manzanera, 1998; 2010; 2011), que se repasará más adelante, como en la editorial generalista (aunque muy especializada en la autoayuda y el esoterismo) Martínez Roca (Manzanera, 1999; 2003) ${ }^{13}$. En esta misma editorial ha publicado en 2006, bajo el apelativo de Lama Blanco (Sakya Tashi Ling, 2006), el catalán Francesc Padró López (nombrado también por sus seguidores como Lama Jamyang Tashi Dorje Rinpoché) que es el líder de uno de los colectivos budistas españoles más mediáticos, en especial por los discos de éxito de música tibetana (bajo el nombre Monjes Budistas) que han producido, y que se centra en el monasterio Sakya Tashi Ling, sito en la provincia de Barcelona. Han producido en un sello propio también un libro, Live peace y en la editorial Aguilar un manual de cocina budista (Sakya Tashi Ling, 2007; 2008).

12 Incluye reediciones de obras de raíz teosófica como las de Olcott (2010), Leadbeater (2011) o de Sinnett (2011) o libros de maestros internacionales como Thich Nhat Hahn (2005), o de autores del budismo del sur como el alemán Nyanaponika (2005; 2006; 2007ab; 2014a-b), los srilanqueses Piyadassi (2008) y Narada Thera (2008) o el birmano Mahasi Sayadaw (2008), pero también publicando a otros autores españoles, como el prolífico Ramiro Calle (2014, del que hay sobre budismo casi una veintena de libros en muy diversas editoriales, algunas obras muy tempranas: Calle, 1970; 1980a-b; 1981; 1984; 1988a-b; 1994; 1998; 2001; 2004a-b; 2005; 2007a-b; 2009; 2011), o al mexicano Senge Dorje-Víctor M. Flores (2008).

13 En Martínez Roca se han publicado varios libros del actual Dalai Lama (1995; 1998d; 1999b/2005, 2016d). Se empezó publicando un libro de Jorge Colomar (1974) sobre el zen, la introducción de Blofeld (1979), un trabajo de Christmas Humphreys (1985, en otras editoriales 2005a-b) y también otro de Ramiro Calle (2007a). Destaca el tratado de meditación de Amadeo Solé-Leris (1986) que cuenta con diversas ediciones en otras lenguas. 
En otros casos encontramos a grupos en España organizados en torno a maestros de proyección internacional. Uno de ellos es Sogyal Rimpoché, líder de la red internacional Rigpa, que tiene casi una decena de centros en España. Es el autor de uno de los bestsellers budistas a escala mundial, traducido a docenas de idiomas, El libro tibetano de la vida y de la muerte (Sogyal, 1994), que ha publicado en traducción al español en la editorial Urano junto a otros dos de sus libros (Sogyal, 1996a; 2004). Se trata de una editorial con una quincena de títulos budistas en catálogo (en un fondo de más de un millar de libros) ${ }^{14}$. Ha publicado también en Olañeta (Sogyal, 1996b), y en catalán su gran éxito editorial (Sogyal, 2011) en la editorial Dipankara, que se revisará en el apartado siguiente.

Otro maestro internacional notable, con la particularidad de que reside la mayor parte del año en nuestro país es Namkhai Norbu, que aúna su calidad de tulku reconocido y maestro del dzogchen con la de profesor universitario retirado y tiene en Tenerife, en el denominado Dzamling Gar, el centro principal de la red mundial que preside. El grupo que lidera, la Dzogchen International Community, regenta una editorial propia, Shang Shung, con sede en Italia, que ha publicado decenas de sus libros en inglés. Pero en España utiliza editoriales generalistas aunque con una fuerte presencia de textos budistas en el catálogo, como Kairós (Namkhai, 1996; 2008; 2012; 2015; 2017), pero también ediciones La Llave (Namkhai, 2002), donde también ha publicado su discípulo venezolano Elías Capriles (2000) o Libros de la Liebre de Marzo (Namkhai, 2007), además de la especializada Ediciones Dharma (Namkhai, 1997).

Ediciones La Llave tiene un fondo de budismo que representa el 15\% de su catálogo ${ }^{15}$ que incluye también, por ejemplo, a maestros del colectivo internacional Shambala, que también tiene una destacable presencia en nuestro país, con un centro en Madrid muy activo y una página web en la que incluso promocionan los libros de los autores, en diferentes editoriales, que asocian con su orientación. En La Llave se han publicado tanto obras de su fundador, el célebre y muy prolífico Chögyam Trungpa (2003b), como de su hijo, Sakyong Mipham (2015;

\footnotetext{
14 Incluye autores muy significativos y famosos como Matthieu Ricard (1998; 2001; 2005; 2009; 2016), Thich Nhat Hahn, del que se hablará más adelante, Tarthang Tulku (2010) o el ya citado Robert Thurman (2000).

15 La Llave también ha publicado obras de Batchelor (2012), de pioneras como Alexandra David-Neel (2001; para otras obras suyas, publicadas en español desde antiguo: 1929; 1942; 1978; 1989; 1990; 2002) o de autores como Chökyi (2003), Tarthang Tulku (2001; 2002; 2003) o Thurman (2012).
} 
2016). Pero los maestros del colectivo Shambala se han prodigado también en otras editoriales. Trungpa, dada su proverbial capacidad de comunicación y su temprano interés por introducir el budismo tibetano entre occidentales, tiene obras traducidas en muchas editoriales como Kairós, donde se publicó su célebre Amanecer del Tantra (Trungpa, 1976) y luego una decena de sus títulos (Trungpa, 1986; 1989; 1995; 1998a; 2002; 2007; 2010; 2011; 2016), pero también en la editorial MTM (Trungpa, 1991a-b; 2001) ${ }^{16}$ donde hay también un trabajo biográfico sobre él (Midal, 2004). Otras editoriales que han publicado a Trungpa han sido Edaf (Trungpa, 1993) ${ }^{17}$, Edhasa ${ }^{18}$ en cuyo catálogo está el influyente Más allá del materialismo espiritual (Trungpa, 1985), pero también Dharma (que repasaremos en el apartado siguiente), Oniro (Trungpa, 1998b) o Gaia (Trungpa, 2009), que ahora revisaremos pues tienen en sus catálogos más obras asociables a Shambala. Por su parte Sakyong Mipham $(2003 ; 2007)$ ha sido publicado también por la editorial de inspiración católica Desclée de Brouwer ${ }^{19}$ y por Oniro, editorial que apuesta por el perfil de la autoayuda pero con un fondo de obras budistas muy destacado que supera el medio centenar y ronda el 15\% de su catá$\operatorname{logo} o^{20}$, aunque en los últimos años ha reducido su producción de libros budistas, como parece ocurrir en otras editoriales del grupo Planeta, en el que han terminado siendo absorbidas algunas otras de las dedicadas a temas orientalistas o con algunos títulos de budismo. Es el caso de $\mathrm{Barral}^{21}$, una de las primeras en incluir

16 En MTM se incluye también un libro del maestro japonés Yamahata (2005), que fundó el centro zen Jiko-An en las alpujarras granadinas o también un trabajo de Judith SimmerBrown (2002).

17 Hay en Edaf también obras de Thomas Cleary, William Hart, Thich Nhat Hahn (1996b), Boddhi Bikkhu, Ramiro Calle (2007b), Miguel Fraile (1993) o John Blofeld (1981).

18 En Edhasa apareció una obra clave sobre el budismo adaptado a Occidente de Alan Watts (1971, de las primeras sobre el zen en España) y una de las de Alexandra David-Neel (1978).

19 En esta editorial hay también obras asociables al zen en gran medida desbudistizado como el que propone Rafael Redondo (2005; 2008; 2010; 2015, en la línea de su maestro Willigis Jäger), pero también de Dumoulin (2002), traducciones de los investigadores de Buenos Aires Fernando Tola y Carmen Dragonetti (2000; y 2002; 2006; 2010 en otras editoriales espańolas) o de Robert Kennedy (2008) sobre cristianismo budista.

20 Incluye grandes maestros de impacto en Occidente como Thich Nhat Hahn (con una veintena larga de obras que incluso forman una colección independiente), Shunryu Suzuki (2003; 2004), Maezumi (2003), Ajahn Chah (2005), Seung Sahn (2010), Deshimaru (2011; también en otras editoriales 1994 b o 1995, además de las obras antes citadas en Kairós y otras) o el actual Dalai Lama (2000a; 2002a; 2004a-b; 2006b) o maestros occidentales como Sangharakshita (1998; 1999; 2001), Philip Kapleau (1999), Steve Hagen (2007), Ajahn Sumano (2013) o el monje católico Thomas Merton (2004) sobre budismo y cristianismo.

21 Autores tempranos españoles sobre el zen fueron Antolin y Embid (1977) o Moreno Lara (1978; también 1979 en la editorial Comunicación Literaria). Antes se publicó el de Glasenapp (1974) que en el título evidenciaba el carácter no teísta del budismo, el de Lalou (1974) 
títulos de este tipo en la España de la Transición, o la ya citada Martínez Roca, o Zenith ${ }^{22}$, o especialmente Paidós ${ }^{23}$, que incluye una prestigiosa colección, Paidos orientalia, donde se han publicado libros clásicos de la erudición occidental como Las religiones del Tíbet de Giuseppe Tucci (2012), que fue la persona que, además, introdujo a Namkhai Norbu en la universidad italiana. Volviendo al contexto de intereses de la red Shambala, en la editorial Imagina (que se revisará en el apartado siguiente) ha visto la luz una obra del controvertido y malogrado discípulo de Trungpa, el estadounidense Ösel Tendzin-Frederick Rich (2004). Imagina es una de las editoriales donde ha publicado quizá la que se considera la más famosa de las discípulas de Trungpa, la estadounidense Pema Chödron (2004), que también ha sido traducida en Oniro (Chödron, 1998; 2002), Sirio (Chödron, 2013a); Rigden (Chödron, 2012) o Gaia (Chödron, 1999; 2013b; 2016). Esta última editorial ha traducido libros cercanos a la propuesta de Shambala como el de Jeremy Hayward (1998) o la edición de Trungpa y Fremantle (2009) del Bardo Thödol, además de autores de otras perspectivas como Tenzin Wangyal (2013a-b; 2017), el fundador de Ligmincha, asociado con la vía del bön y que tiene grupos de seguidores en España, entre otros autores ${ }^{24}$. En el trabajo de traducción de los libros de los escritores asociables con Shambala hay que destacar a Alfonso Taboada, que ha vertido, en ocasiones en colaboración con otros traductores de temas budistas (destacando también Ferran Mestanza) a Trungpa para Kairós (Trungpa, 1995; 1998a; 2002; 2007), MTM (Trungpa, 1991a), a Sakyong para Desclée de Brouwer (Sakyong, 2003) y Oniro (Sakyong, 2007), a Ösel Tendzin para Imagina (Tendzin, 2004) o a Pema Chödron para Imagina (Chödron, 2004) o Rigden (Chödron, 2012). En ocasiones este tipo de figuras

sobre las religiones del Tíbet y el del gran orientalista Giuseppe Tucci (1973) sobre el mandala (tanto budista como hinduista), más tarde el de Lenoir (2000) sobre el budismo occidental, que se evidencia que ha sido un interés peculiar del editor.

22 Donde se están publicando obras del actual Dalai Lama (2010a; 2011b) o las recientes de Thich Nhat Hahn (2018a-c).

23 La editorial Paidós ha publicado desde 1980 obras del zen como la introducción de Eugen Herrigel (1980) o trabajos de Deshimaru (1985), de Daisetz Teitaro Suzuki (1996; 2001) y de Thich Nhat Hahn (1999; 2017b), también de autores del budismo tibetano como el actual Dalai Lama (2008b; 2010b) o Robert Thurman (2006), o de orientaciones algo inclasificables como la de Ananda Coomaraswamy (1989; también 2000 en Olañeta) o el trabajo de Denis Gira (2010), a los que se ańade un instrumento clave para el estudio en forma de diccionario de religiones orientales (Fischer-Schreiber, 1993).

24 El fondo de obras budistas en Gaia incluye obras zen de impacto como el célebre Los tres pilares del zen de Kapleau (1994), el clásico de Shunryu Suzuki (2012) o los de Joko Beck (2008; 2012), obras del budismo tibetano como la del Dalai Lama y Varela (2009b) o la de Chöky Nyima (2001), de representantes del budismo occidental como Kornfield (2013) o Batchelor (2008). 
que aúnan la cualidad de miembros de una comunidad budista con el interés y la capacidad para traducir y promover la publicación de esas traducciones, resultan un eslabón clave para que la visibilización editorial del budismo se materialice. En el apartado siguiente citaremos a algunos y en especial a Xavi Alongina, por su implicación también en este aspecto algo invisibilizado en ocasiones, el de la traducción, del trabajo editorial, pero los casos son numerosos y se tendrán en cuenta algunos al reflejarlos en la bibliografía.

La ya citada editorial la Llave ha publicado extensamente a otro maestro internacional residente en nuestro país, Dhiravamsa (2001a-b; 2004a; 2009a), tailandés de nacimiento pero nacionalizado español, que tiene grupos de seguidores tanto en Canarias, donde reside, como en el País Vasco, Zaragoza y Cataluña y cuyas publicaciones en español se prodigan también en ediciones Mandala (Dhiravamsa, 2008b; 2009b; 2012a) y la mayoría en las ediciones de La Liebre de Marzo (Dhiravamsa, 1991; 1992; 1997; 2004b; 2007; 2008a; 2012b; 2014; 2015). Esta última editorial ha publicado más de una veintena de obras de autores budistas, que configuran un destacable $15 \%$ de su catálogo ${ }^{25}$. No es ajena la elección de editoriales en este caso a la importancia de sus seguidores en la zona donde tienen sus sedes dichas editoriales, La Llave es de Vitoria, Liebre de Marzo de Barcelona.

Otro maestro con media docena de grupos de seguidores en España es Yongey Mingyur Rimpoché, líder de la red internacional Tergar, en España ha publicado en la editorial Rigden Institut Gestalt (Yongey, 2010; 2012) ${ }^{26}$ centrada en las terapias alternativas donde también ha publicado el actual Dalai Lama (2013a) o Dzigar Kongtrül Rinpoché (2006; 2008).

Uno de los maestros budistas de impacto internacional con más lectores en la actualidad es Thich Nhat Hahn, sus seguidores en España son muy numerosos y se aglutinan en torno a 60 grupos de prácticas por todo el país. Ha publicado cerca de ochenta libros en España, muchos de ellos con un éxito que ha requerido numerosas reediciones. Aunque algunos derivan en la autoayuda desde una

25 Que incluye libros de temas específicos del budismo occidental (por ejemplo Goldstein, 2005 o Wettering, 2000) como de maestros occidentales y orientales del vipasana como Jack Kornfield (1997; 2001; 2010), del zen coreano, como Seung Sahn (1991; 2002), del dzogchen como Namkhai Norbu (2007) o del zen occidental como el controvertido Dennis Merzel (2008).

26 Tiene publicaciones también en Kairós (2016) y en la editorial Granica (2008), donde ha publicado también Pujol (2003) o el célebre Budismo para dummies de Landaw (2009). 
sensibilidad budista, en la gran mayoría las implicaciones doctrinales, éticas y formales del budismo conforman el discurso. Se ha prodigado en muchas editoriales españolas, con una treintena de títulos en Oniro (destacando Nhat, 2001; 2002; 2003; 2009; 2010; 2014b, los más recientes 2018a-c en Zenith, pero también en Paidos: 1999; 2017b, todos del mismo grupo editorial), una quincena en Kairós (destacan Nhat, 1996a; 2000; 2011; 2013b; 2014a; 2017a), en Librería Argentina (Nhat, 2005), Urano (Nhat, 2016), La Llave, Obelisco, Jaguar, DeBolsillo, Gaia, Neo Person, Edaf (Nhat, 1996b) y también en Dharma, la más destacada editorial budista española donde publicó algunas de sus primeras obras (Nhat, 1993a-b, también 2007), aunque hay que evidenciar que su primer título en nuestro idioma lo publicó en Sígueme (Nhat, 1978), una editorial confesional católica. Y es que hay que tener en cuenta que su propuesta budista se caracteriza por tender puentes con el catolicismo que se evidencia en que un cierto número de quienes le siguen se siguen identificando como cristianos. Este asunto del «bilingüismo religioso» (expresión que tomamos de Ana María Schlüter, 2008b) lo volveremos a traer a colación brevemente en el apartado final.

El autor budista con mayor número de obras publicadas en España es, sin duda, el actual Dalai Lama. El impacto de sus libros se explica al aglutinar la convergencia de grupos en torno a su figura por parte no solo de la escuela gelugpa a la que pertenece, sino por casi todas las sensibilidades del budismo tibetano (con la excepción notable de la Nueva Tradición Kadampa ${ }^{27}$, que luego revisaremos, puesto que regentan una editorial budista propia en España) y por la simpatía de muchos budistas de otras orientaciones y también de lectores no budistas. $\mathrm{Ha}$ publicado un largo centenar de libros en traducción tanto en castellano como en catalán en cuarenta editoriales distintas entre las que destaca una quincena en Kairós (en especial Dalai Lama, 2001c; 2002b; 2004f-g; 2007c; 2008c; 2009c; 2013b; 2013c; 2014; 2015), otro tanto en Oniro (destacan Dalai Lama, 2000a; 2002a; 2004b-c; 2006b) y otras editoriales de grupo como Martínez Roca (Dalai Lama, 1995; 1998d; 1999b; 2016d), Zenith (Dalai Lama, 2010a; 2011b) o Paidós (Dalai Lama, 2008b; 2010b). También destaca Olañeta (Dalai Lama, 1997c; 1998a-b-c; 2001b; 2004d), Grijalbo (2000b; 2001d; 2001e; 2006a; 2007d; 2016a), muchas reediciones en Debolsillo (Dalai Lama, 2003b; 2011 a destacan por no ser reediciones), en el Círculo de Lectores, Kailas (Dalai Lama, 2004b; e) o Viena (Dalai Lama, 2004g; 2005a), entre otras editoriales ${ }^{28}$.

27 Un ejemplo de su empeño en la senda contraria: Western Shugden Society, 2010.

28 Hay que añadir Plaza y Janés (por ejemplo Dalai Lama, 1998g), Icaria (Dalai Lama, $1994 b$ con una introducción de Raimon Panikkar, del que hay que destacar su trabajo sobre 
El primer libro que publicó fue en Noguer (Dalai Lama, 1962) exponiendo su huida del Tíbet, y los inmediatos posteriores en Dharma que suman casi una quincena o en Cárcamo, con traducción de Villalba (Dalai Lama, 1982), como vimos. Resulta particularmente significativo que haya publicado en tres editoriales de ideario cristiano, como son PPC (Dalai Lama, 1997b, sobre Jesús desde la óptica budista), Sal Terrae (Dalai Lama, 2009a) o Herder (Dalai Lama, 2016c), cuestión que no desentona con la apuesta por el diálogo interreligioso del autor.

\section{La relevancia de las editoriales confesionales budistas}

Hemos visto hasta ahora al budismo como propuesta en editoriales de espectro general. Si obviamos las que incluyen solo algunos títulos de modo esporádico, hay cuatro tipos principales de orientaciones editoriales entre las que tienen un catálogo de libros budistas de cierta relevancia (rondando o superando el 10\% de su producción). La más antigua consistió en incluir al budismo y muy especialmente el tibetano, por su prestigio en el que no fue secundaria la importancia que se le dio en la Sociedad Teosófica, como ingrediente de catálogos centrados en el esoterismo, como ejemplifica la editorial Cárcamo o la primera etapa de la editorial Martínez Roca. También en el pasado, la apuesta por la contracultura en las orientaciones de algunas editoriales llevó a la inclusión en sus catálogos de obras del budismo zen. Ambas tendencias han convergido en el mantenimiento en épocas más recientes del budismo en editoriales que se han orientado hacia la autoayuda y las terapias alternativas. La cuarta orientación tiene que ver con editoriales que incluyen el orientalismo entre sus intereses y en las que el budismo resulta un ingrediente destacado, siendo el mejor ejemplo la editorial Kairós, por lo extenso de su catálogo, pero también Paidós, entre otras.

Hay un segundo conjunto de editoriales, poco numeroso, que agruparía las que tienen un catálogo de obras budistas que representa la casi totalidad de sus

el budismo en Siruela: Panikkar, 1996), El País, Helios (Dalai Lama, 1997a), Sirio (Dalai Lama, 1998e), Apóstrofe, Ediciones B (Dalai Lama, 1999a), Integral (Dalai Lama, 1999c), Del Bronce, RBA (Dalai Lama, 2003a), Belacqua, Luciérnaga, Ediciones i (Dalai Lama, 2007b), Alienta (Dalai Lama, 2008a), Obelisco, Gaia o Rigden Institut Gestalt (Dalai Lama, 2013a). 
fondos, hemos citado ya a tres de ellas, Dipankara, Rigden e Imagina. La primera fue una editorial con un catálogo exclusivamente dedicado a temas budistas, y que publicó entre 2010 y 2012 una quincena de libros tanto en catalán como en castellano destacando autores como Sogyal Rinpoché (2011), Thondup Tulku (2010) sobre los gtermas tibetanos, con textos clásicos (Tsang Nyon Heruka, 2012b) o Zhang (2011) sobre el ch'an. Rigden publicó a Khenpo Tsultrim Gyamtso (2007) y a la ya citada Pema Chödron (2012). Imagina es una editorial que se ha centrado casi exclusivamente en publicar libros del budismo tibetano en un catálogo con una veintena larga de obras publicadas entre 1997 y 2006 en el que se incluyen lamas de gran renombre como el primer Jamgön Kongtrül (1997ac), el XII Drukpa (2000), Dilgo Kyentse Rinpoché (1998a-b; 2005), Guendune Rinpoché (1997; 1999), Gyetrul Jigme Norbou (1997; 1998), Patrul Rinpoché (1999), Bokar Rinpoché (2005) o también el actual Dalai Lama (1999d), así como obras tibetanas traducidas como las de Ińaki Preciado (1998; 2000), o a autores occidentales como los antes citados Ösel Tendzin (2004) o Pema Chödron (2004), y Grasdorff (2005), con una monografía sobre el Panchen Lama o, más allá de lo tibetano, un libro sobre el vipassana de Larry Rosenberg (2005). A pesar de presentar un catálogo notable, con muchos autores que coinciden con editoriales de grupos budistas como Dharma, Amara o Chabsel, Imagina es una propuesta editorial que no se relaciona de modo directo con ningún grupo budista en concreto y mezcla maestros de orientaciones diferentes en la línea del movimiento rimé tibetano y su apuesta por la confluencia entre escuelas y linajes.

Lo contrario ocurre con las editoriales que ahora repasaremos, que tienen directa o cercana relación con algún grupo o red budista con presencia en nuestro país. Con anterioridad hemos citado algunas de las que han producido libros de modo esporádico, y los editaban bajo la denominación del propio grupo. Lo ha hecho la Comunidad Budista Soto Zen (Villalba, 1997; Sawaki, 2012), el templo Seikyuji (Triet, 2002) o lo está haciendo el dojo Kannon de Barcelona (Salas, 2016; 2017a), pero se trata de una labor que no ha solido exceder alguna primera tentativa. En esta misma línea están intentos de edición por colectivos budistas como la Coordinadora Catalana d'Entitats Budistes que ha publicado un único libro, cuyo autor ha sido Basili Llorca (2009), la Fundació Casa del Tibet que ha publicado un opúsculo del Dalai Lama (2007a) en tres idiomas o la publicación por sus seguidores de la obra autobiográfica de Nydahl (1989), el líder de la red mundial Diamond Way que regenta en España una veintena de centros de meditación además del monasterio Karma Guen en Vélez Málaga o el estupa de Benalmádena. 
Pero ahora repasaremos el siguiente paso, cuando los primeros intentos fructifican en la conformación de catálogos que terminan alcanzando decenas de títulos. En ocasiones llegan a desbordar los límites de sus propios linajes y orientaciones e incluyen obras budistas de espectro general. Hay dos ejemplos que destacaremos, que además se han de asociar a personas cuya implicación en la labor editorial ha determinado el éxito de las propuestas: las editoriales Dharma y Amara.

La Fundación para Preservar la Tradición Mahayana (FPTM), es uno de los colectivos budistas con presencia más temprana en España, que parte de la visita a Ibiza de los lamas Yeshé y Zopa en 1977, y que cuenta con una decena de centros, entre los que destaca Osel Ling, en la Alpujarra granadina, donde se gestó uno de los episodios más notables del budismo español, que fue el reconocimiento del español Osel Hita como reencarnación del lama Yeshé y que fue narrado por su madre (Torres, 1994, más datos en Mackenzie-Tenzin Palmo-, 1989; 1998, otro trabajo suyo en RBA: Mackenzie, 2000) ${ }^{29}$. La FPTM se relaciona con la editorial budista más importante y con un catálogo más nutrido y de presencia más antigua y continuada de España: ediciones Dharma. Se fundó en 1982 y hasta su fallecimiento Xavi Alongina (1952-2017) la dirigió y le imprimió la línea editorial y promovió su éxito. El catálogo, que ronda los 150 títulos, incluye un buen número de obras de los lamas y maestros de orientación gelugpa o asociados al linaje y las enseńanzas de la FPTM. Empezó publicando una entrevista al actual Dalai Lama (1982b) con la que se inauguró la editorial e incluye casi una quincena de sus obras que van desde opúsculos (Dalai Lama, 1987; 1990a-b; 2004h), como su discurso de recepción del Premio Nobel (Dalai Lama, 1990a) o la publicación de su reunión con científicos (Dalai Lama, 1990b), a trabajos de gran envergadura como un texto preparatorio de la iniciación de Kalachakra que llevó a cabo en Barcelona (Dalai Lama, 1994a) y desde comentarios de textos clásicos (Dalai Lama, 1996b; 1998f; 2003c) a recientes reflexiones sobre el futuro (Dalai Lama, 2016b), añadiéndose obras más generales sobre la compasión, la disciplina mental o la historia tibetana (Dalai Lama, 1994c-d; 2005b; 2007a). Pero es el esfuerzo de publicación de las obras de los lamas fundadores de la FPMT el que más libros ha producido. Aparecen tanto la reedición del primer libro en español, obra de ambos (Yeshé y Zopa, 1991), como quince libros del primero, recopilando en ocasiones enseñanzas impartidas en nuestro

29 RBA tiene otros autores budistas en catálogo como Les Kaye (2001) y muchas reediciones de obras previamente publicadas del Dalai Lama, de Deshimaru (1994b; 2003b), de Daisetz Teitaro Suzuki, Alan Watts, Trungpa, Merton o Thich Nhat Hahn, entre otros. 
país (Yeshé, 1988a-b; 1989; 1993; 1995; 1996; 2000; 2001; 2003; 2005; 2008; 2009; 2013; 2014; 2016) y otros tantos del segundo (Zopa, 1989; 1994; 1995; 1999; 2001; 2009; 2010; 2011; 2012a; 2013c; 2014a; 2015; 2016). Se añaden obras de los principales lamas que han venido a España en el contexto de la labor de la FPTM como Song Rinpoché (1989) o Gueshe Jampel Senghe (Senghe 1984); que residieron en España como Gueshe Tempa Dhargey (1990), o que viven en nuestro país como Gueshe Lobsang Tsultrim (Tsultrim, 1988; 1991a-b; 1999; 2001; 2011), que es el lama que más tiempo lleva en España (Alongina, 1999; Mínguez, 2006), aunque se haya apartado de la FPTM y haya creado un grupo propio, Tara, con sede en Barcelona (donde ha publicado materiales audiovisuales de sus enseñanzas). Especial mención merece Gueshe Tamding Gyatso con dos obras en ediciones Dharma (Gyatso, 2005, 2015a), aunque sea la editorial Amara y en la actualidad la Fundación Chu Sup Tsang las que hayan publicado principalmente la obra de este lama, que vivió muchos años en España y que en su autobiografía en español (no así en su versión tibetana) se nombra como un "lama español nacido en el Tíbet» (Gyatso, 2015c). En Dharma se han publicado también traducciones de muchos clásicos del budismo tibetano como obras de Atisha, Tsongkapa o la vida de Marpa (Tsang Nyon Heruka, 2012b, traducida por Agustín Araque a quien se debe una introducción al budismo -Araque, 2008-). De entre los autores españoles que están o han estado asociados a la FPTM destacan las obras Juan Manzanera (1998; 2010; 2011) o los trabajos de traducción de Champa Shenpen-Jesús Revert (Champa, 2000; 2017 entre otros), de entre los extranjeros destacan el estadounidense Jonathan Landaw (1990, compilador del lama Yeshé, 1988b), el tibetano Thubten Soepa (2011) o el australiano Thubten Dondrub. Otros autores asociables a la escuela gelugpa en la que se inserta la FPTM, como Dagyap Rinpoché (2006), Jampa Tegchok (1994; 1995), la monja estadounidense Thubten Chodron (1989; 1993; 2012; también 2002 en Alianza editorial), el tibetano afincado en España Tritul Nyare Rimpoché (2009), Kathleen McDonald, Jeffrey Hopkins o Guy Newland. También en el extenso catálogo de Dharma hay autores tibetanos de otras orientaciones diferentes a la gelugpa como el actual Karmapa que reconoce el Dalai Lama (Trinle, 2014b), el Tai Situ (2017), Bokar Rinpoché (1990; 1997; 2004b), Chögyam Trungpa (2003a), Akong Rinpoché (1993), Dilgo Khyentse Rinpoché (1994; 2011), Chimed Rigdzin Rimpoché (2017) y su discípulo James Low (2010; 2013a-b), Kunzang Palden (2015) o Namkhai Norbu (1997). En menor medida han publicado a autores budistas de escuelas no tibetanas como Thich Nhat Hahn (1993a-b; 2007), Ajahn Sumedho, Nyanaponika Thera (2002), Joseph Goldstein (1995; 1998; 2009), Jack Kornfield (2000), Seung Sahn (1998), Sangharakshita (2008) o el español Saya Kunsal Kassapa (2011a), 
ya citado, entre otros. Además ediciones Dharma publicó la revista budista española que ha tenido un mayor impacto, Cuadernos de budismo, que tenía una periodicidad trimestral y comenzó a publicarse en 1992 y cesó en 2012 después de alcanzar 83 números y que fue la continuación de Cuadernos de meditación budista que se editó desde 1986 a 1992. Fueron elementos clave en la visibilización del budismo español y también de las novedades editoriales que reseńaban en sus páginas durante el cuarto de siglo largo en el que ambas publicaciones periódicas se mantuvieron en circulación. La FPTM en España puso en marcha en 2011 una nueva propuesta, Ediciones Mahayana, que ha publicado tanto libros para la comercialización abierta, como otros para el uso más interno y restringido (que desarrollan las oraciones que se usan en los centros $\mathrm{y}$ otros materiales de este tipo o prácticas que exigen iniciaciones previas), aunque todos ellos se ofrecen en su página web, que se incluye en la muy cuidada de Ediciones Dharma. Entre los libros de circulación general destacan las enseñanzas del Lama Zopa relativas a la muerte (Zopa, 2012b-c), pero también exponiendo rituales (Zopa, 2013a-b; 2014b), obras de los lamas Yeshé y Zopa (2013), textos clásicos de Shantideva (2013), del Séptimo Dalai Lama (2013) o sutras como el del Cortador Vajra o el de Tsedo.

Esta mezcla de productos editoriales abiertos y restringidos los encontramos también en otro grupo, Thubten Dargye Ling de Madrid, liderado por el lama Tsering Palden, que en sus primeros años de estancia en Espańa (donde lleva desde el 2000) estuvo asociado con la FPTM. En la página web del grupo se ofrece mucho material autoeditado en pdf, pero con una calidad visual casi profesional, incluyendo tanto material de acceso libre como material de acceso restringido (llamada biblioteca privada frente a la pública). Pero en 2016 han dado el paso de convertir en libro físico, bajo el amparo de una editorial propia, denominada Delam, una primera obra de su líder (Palden, 2016).

Semillero de editoriales ha sido la presencia en España de Gueshe Tamding Gyatso (Alongina, 1996), un muy notable erudito tibetano que recaló en Menorca en 1987, tenía la nacionalidad española y vivió en nuestro país hasta su nombramiento como abad del monasterio de Ganden Sartse en la India en 2001 y su muerte al año siguiente. Uno de sus discípulos, Isidro Gordi fundó una editorial budista especializada que empezó sus publicaciones monográficas al final de la década de 1980: Ediciones Amara. Supera los 60 títulos y comenzó justamente con las obras del que fue su maestro, Tamding Gyatso, del que ha publicado más de una decena de libros traducidos por él mismo y por Marta Moll (Gyatso, 1989; 1990; 1991; 1992; 1993; 1994; 1995; 1997a-c; 1998) o publicadas 
a su nombre pero recopilando las enseñanzas del maestro (Gordi, 2011a; 2012; 2013b). También publica trabajos de su actual maestro, Michael Roach, del que ha publicado más de media docena de títulos (Roach, 2001; 2003a-b; 2008; 2011). Y en el pasado publicó dos obras de Gueshe Kelsang Gyatso (Kelsang, 1989; 1992) e incluso tradujo otra (Kelsang, 1983), antes de que se produjese la ruptura que Alongina (1992) denominó «tormenta en el Instituto Dharma» y que fue consecutiva a la separación de la Nueva Tradición Kadampa del budismo gelugpa y tuvo en Menorca su epicentro en España. En Amara se incluyen obras de los grandes líderes del budismo tibetano, de los actuales Dalai Lama (1996a; 1999b) y Sakya Trizin (2012), y entre los clásicos, del primer Panchen Lama (2017), pero también obras de Tsongkapa (1998) o Shantideva (1995). De entre los maestros tibetanos recientes destacan los tres libros de Gonsar Rimpoché (1994; 1996; 1999), uno de Dilgo Khyentse Rinpoché (2008), otros de Pabongka Rinpoché (2016), Dagyap Rinpoché (1997), Jampa Tegchok (2016), Traleg Kyagbon (2015) o Choedak Yuthok (2003). Destaca en especial la media docena de libros que han publicado del Gueshe Tashi Tsering (2006; 2007; 2009; 2010; 2012; 2016; también 2003, pero en otra editorial, Amaranto, con sus memorias) o del británico Janpa Thaye (2009). Más allá de los libros de budismo tibetano el catálogo incluye al maestro tailandés Ajahn Buddhadasa (2008; 2012) o el primer libro de Stephen Batchelor (2000) traducido a nuestra lengua. Hay que añadir también la decena de libros propios que en su editorial ha publicado Isidro Gordi (1994; 2004; 2007; 2008; 2009; 2011b; 2013a; 2016), muy centrados en la meditación (y el más reciente nombrandolo mindfulness), que se añaden a los antes citados (Gordi, 2011a; 2012; 2013b) de exposición de las enseñanzas de su maestro Tamding Gyatso.

Justamente ha tomado el relevo de Amara en la publicación de las obras de Gueshe Tamding Gyatso la editorial de la Fundación Chu Sup Tsang. Forma parte de la red Ganden Chöling, una de las más activas en nuestro país en la actualidad y aglutina una veintena de centros y el monasterio Chu Sup Tsang en la provincia de Orense. La editorial ha coordinado los esfuerzos previos que se materializaron en publicaciones de uso interno y en revistas de difusión restringida como La luz del Dharma o Ganden. Hay publicada una treintena de títulos desde 2010 en que comenzaron publicando libros del actual líder del grupo, Tenzing Tamding, sobrino de Tamding Gyatso. Se incluyen los textos de las enseñanzas anuales en la sede de la fundación (Tenzing, 2010; 2011; 2012a; 2013a; 2014a; 2015a; 2016a; 2017a), comentarios de textos clásicos (Tenzing, 2012b-c), obras sobre la felicidad (con ediciones también en inglés y alemán: Tenzing, 2014c; 2015c; 2016c-d; 2017d), la muerte y la salud (Tenzing, 2008 
-en otra editorial-; 2014b; 2014d; 2016b; 2015b), y rituales y cuestiones generales (Tenzing, 2013b-c; 2015d; 2017b-c). Además de las obras de Tamding Gyatso (2013a-c; 2014; 2015b-c), de las que han publicado media docena entre las que destaca la ya citada autobiografía, hay que citar los trabajos de otro de los lamas del grupo, Tritul Nyare Rimpoché, (2016; 2017), vicepresidente de la Fundación y lama residente del Centro Chakrasamvara de Sevilla. Fuera de los tres maestros del grupo han publicado en la editorial el texto de las conferencias que desarrolló en el monasterio de la fundación el maestro del budismo chan Fan Ta Shi Yuan traducidas por Tenzing Tamding (Yuan, 2012).

Tras la separación en Menorca de los seguidores de Gueshe Kelsang Gyatso del grupo de Tamding Gyatso y la apuesta de los primeros por desarrollar la red de la Nueva Tradición Kadampa en España, este colectivo se dotó de una editorial propia, Tharpa, la tercera editorial que surge del semillero que fue el grupo de Menorca que lideraba Tamding Gyatso. En este caso la labor de publicación está centrada en las traducciones al español, que llegan a la treintena, de las obras del líder del colectivo, Gueshe Kelsang Gyatso (1993; 1994; 1995a-b; 1996a-b; 1998; 1999; 2001a-b; 2003; 2004; 2005; 2006a-b; 2007; 2008; 2009; 2010; 2011a-b; 2013a-e; 2014; 2016; 2017a-b, con múltiples reediciones y en algún caso retomando obras previamente publicadas en otras editoriales como Kelsang, 1988 o 1991), aunque también han publicado el clásico de Shantideva (2004). Tharpa ofrece títulos al alcance de cualquier lector sobre temas que en otras escuelas del budismo tibetano se estiman enseñanzas que se transmiten solo cuando se ha alcanzado un nivel de práctica y compromiso contrastados y por tanto no se ofrecen con un acceso no restringido. Estas obras son la base para los programas de estudio que organiza el grupo para sus seguidores y muchos de ellos se ofrecen también en e-book y como folletos para prácticas específicas. También han publicado, en la línea seguida por la Nueva Tradición Kadampa desde su sede central de Gran Bretaña, un libro muy crítico con el actual Dalai Lama (Western Shugden Society, 2010).

Otra editorial budista española es Chabsöl/Chabsel, que depende del monasterio Dag Shang Kagyu, ubicado en Panillo, Graus, Huesca, y que es el centro de una de las redes del budismo kagyupa más estructuradas en nuestro país y que fundó el gran maestro Kalu Rinpoché, del que han publicado cinco obras (Kalu, 2003; 2006; 2011a-b; 2012). También han publicado un libro del actual abad del monasterio, el lama butanés Drubgyu Tenpa (2012). Se añaden también una quincena de títulos que se suelen inscribir en la línea de la escuela karma kagyu y shangpa kagyu (Riggs, 2005 sobre los maestros de este linaje) entre los que 
destaca Bokar Rinpoché del que han publicado seis libros siendo la editorial en la que más títulos suyos se ofrecen (Bokar, 2004a-c; 2006; 2007; 2010; 2016) y le siguen la editorial Dharma (Bokar, 1990; 1997; 2004b), la editorial Imagina (Bokar, 2005), ediciones B (Bokar, 1998) y una editorial que solo generó un libro (Bokar, 1995) y llevaba el muy simbólico nombre de La auspiciosa roca blanca, y se asociaba con los seguidores de Kalu Rinpoché (a quien se dedica el libro). En Chabsel se han publicado también obras de maestros y maestras que suelen visitar el lugar. Resulta muy interesante la actividad de de Khandro Rinpoché (Khandro, 2010), que evidencia el magisterio que las mujeres están tomando en el budismo occidental, en el que la ya citada Pema Chödron es también ejemplar ${ }^{30}$. En general en el catálogo contamos tanto con obras clásicas como la de Gampopa (2009) o Shantideva (2009), como de autores tibetanos como Jamgön Kongtrül (2017), Dzigar Kongtrül (2015), Gyetrul Jigme Norbou (2003), Thrangu Rinpoché (2014), Khenpo Tsultrim Gyamtso (2006b; 2006c; 2012; también 2006a en Dharma), del francés Cheuky Sengue-François Jacquemart (2007a-b), del ya citado Lama Djinpa-Borja de Arquer (2009) o de Michaela Haas (2015), además, en acceso retringido hay otras obras entre las que destaca la de Karma Sönam Chöpel-Xavier Artigas (1995) narrando los años de fundación del monasterio y la implicación de su fundador Kalu Rinpoché en ellos.

La red Samye Dzong, ya citada, que surgió de las visitas de Akong Rinpoché a Espańa, no regenta una editorial al modo de las que hemos repasado hasta ahora, pero se han embarcado en producciones editoriales ocasionales. En 1983 publicaron tres obras del Tai Situ (1983a-c) y una de Thrangu Rinpoché (1983) en un sello propio (Asociación Dagpo-Samye Dzong) y en 2012 y en el sello Kagyu Samye Dzong Barcelona, publicaron una obra del cabeza del linaje, el Karmapa que el grupo reconoce (Trinle, 2012), o también han propiciado (Trinle, 2008) o influido en la impresión de otra (Trinle, 2014a), además de una obra de Jamgön Kongtrul (2014) que publicaron en la Fundación Rokpa, que dirigía Akong Rinpoché y centralizaba el grupo. Se trata de obras muy centradas en el culto y sus detalles y se difunden principalmente entre los miembros del colectivo.

Hasta ahora hemos repasado editoriales de grupos del budismo tibetano, pero también otras orientaciones budistas han invertido en este tipo de proyectos. Uno de ellos, que se suele enmarcar en el nuevo budismo y lo forman seguidores

30 Resultan interesantes los libros de Rita Gross, 2005, discípula de Khandro Rinpoché, o de Sylvia Wetzel, 2002, que empezó con el Lama Yeshé. 
occidentales y que en el pasado regentó un proyecto editorial ha sido la Comunidad Budista Triratna (antes denominada Amigos de la Orden Budista Occidental). Transformaron en 2010 la editorial Tres Joyas en una librería budista online (www.librosbudistas.com), en la que además de vender publicaciones budistas, ofrecen un buen número de obras descargables desde internet, en particular del británico Sangharakshita (Dennis Philip Edward Lingwood), fundador del colectivo internacional, además de incluir textos del budismo antiguo, de maestros contemporáneos e incluso rarezas como un facsímil del poema Buddha que escribió Federico García Lorca en su juventud. Entre 1993 y 2010 publicaron como Tres Joyas editores/Triratna principalmente obras de Sangharakshita (1993a-b; 1994a-c; 2011a-c; 2012) o de miembros del grupo como Chris Pauling (1993), Nagabodhi (1993), Suvajra (1994) o Paramananda (2010), pero también editaron a un notable y controvertido representante del budismo occidental, el Lama Anagarika Govinda-Ernst Hoffman (2001), del que se han publicado más obras en otras editoriales ${ }^{31}$ o a Zubieta (2001).

Ediciones Civilización Global es la editorial del grupo Soka Gakkai en España, uno de los colectivos que derivan del budismo puesto en marcha en Japón por Nichiren. Publica desde 2005 la revista mensual Civilización Global (antes, desde 1997, se titulaba Visión Global y previamente se llamaba De la victoria, y comenzó a publicarse en 1993 tras la separación entre Soka Gakkai y el grupo Nichiren Shoshu) y también las anuales Ensayos de Budismo y Budismo en diálogo desde 2011. Se ha centrado en la traducción de libros del líder del grupo, Daisaku Ikeda (2008b; 2010b; 2015b; 2016b; 2017b), que además ha sido publicado en diversas editoriales generalistas (Ikeda, 1982; 1988; 1990), destacando sus conversaciones con diversos líderes occidentales. De Ikeda resultan notables sus propuestas de paz que cada año desde 1983 realiza a finales del mes de enero, y cuya traducción al español desde 2008 se realiza en nuestro país (Ikeda, 2008a; 2009; 2010a; 2011; 2012; 2013; 2014; 2015a; 2016a; 2017a). Con anterioridad, Soka Gakkai España, con un sello editorial homónimo, publicaba obras de trabajo para el grupo y también de Ikeda $(1996 ; 1998)$, incluida la serie titulada La nueva revolución humana (Ikeda, 2003, en cuyo volumen 5-6 se incluye el relato de la visita de Ikeda a Espańa en 1961). Antes de la separación de Nichiren Shoshu publicaron la introducción al budismo de Kirimura (1990). De Nichiren han editado la liturgia (Nichiren, 2013) a la que se añade la coedición con la

31 En Eyras tenemos Govinda, 1980; 1981a-b (1992 en la editorial Heptada), se trató de una editorial en la que también han publicado otros occidentales como Nyanaponika TheraSiegmund Feniger (1982) o John Blofeld (1982 para su biografía) 
editorial Herder de los escritos de Nichiren, bajo la supervisión de Carlos Rubio (Nichiren, 2008). Este tipo de coediciones entre editoriales de perfil católico y colectivos que se asientan en la formulación que propuso Nichiren la tenemos también en el caso de la editorial Sígueme que con Kosei Publishing han publicado una versión al español del Sutra del Loto ${ }^{32}$ que ha traducido el jesuita Juan Masià (2009), de quien contamos con diversos trabajos sobre el budismo en editoriales católicas como SM, Sal Terrae, PPC, Desclée de Brouwer o Sígueme (Masià, 1996; 1997; 1998; 2003; 2006; 2007a-b). También en Sígueme publicaron una obra de Niwano (2013), el primer presidente del grupo Rissho Kosei Kai, la célebre reflexión seminal sobre budismo y cristianismo de Henri de Lubac (2006) o el no menos célebre trabajo de Nishida (2006) sobre la nada ${ }^{33}$.

El budismo del sur, menos institucionalizado en España que las propuestas japonesas o tibetanas, tiene también un proyecto editorial en nuestro país. Se trata de la Asociación Hispana de Buddhismo que bajo la dirección de Ricardo Guerrero (que se ha encargado también del papel de traducción) está publicando libros de algunos maestros de esta tradición como Nandisena (2012), Bodhi (2016), Narada (2016) o Dhammasami (2013), pero también de un maestro del chan (Shi Dayuan, 2015). Están optando también, como hemos visto en otros casos (en especial con Tharpa), por el libro electrónico, que se configura como una apuesta de futuro que probablemente hará que muchos otros grupos, que hasta ahora han optado por autoediciones de difusión restringida, los puedan abrir a un horizonte de lectores mucho menos limitado como es el que permite esta tecnología de difusión editorial que multiplicará la visibilización del budismo.

32 Soka Gakkai también ha publicado una traducción del Sutra del loto en 2014.

33 En Herder hay también un trabajo de Ueda (2004) y otro de Nishitani (1999) sobre el vacío, clave en la reflexión budista que permea los planteamientos de la Escuela de Kioto y también un libro de Heisig (2002) sobre la escuela y otro sobre Jesús y el budismo (Heisig, 2007), interesan las reflexiones de este autor en diálogo con Raquel Bouso (2008; 2012) sobre el zen y en general el libro de Amador Vega sobre el tema (Vega, 2002). Herder ha publicado también un libro de Marco Pallis (1986). 


\section{Conclusión}

En suma, del apartado anterior resulta que la puesta en marcha de editoriales budistas ha sido un esfuerzo que han emprendido principalmente grupos españoles asociables con el budismo tibetano, que son los más numerosos, por otra parte. Pero resulta destacado que ningún grupo del budismo zen, salvo los intentos esporádicos antes citados de la Comunidad Budista Soto Zen, el templo Seikyuji y el dojo Kannon de Barcelona, haya puesto en marcha una editorial al estilo de Dharma o Amara, a pesar de la notable producción que el zen ha generado de la que el ejemplo de Dokusho Villalba como autor o traductor es bien significativo. Sin embargo hay un producto editorial, que no podemos tratar en este trabajo con detalle porque no se identifica como budista, que es el zen dirigido hacia practicantes católicos que ha derivado de la escuela japonesa Sanbo Kyodan-Sanbo Zen y que tiene en España grupos institucionalizados, como los que lideran Carmen Monske o Berta Meneses (y que también derivan de un maestro alemán, antiguo miembro de la escuela, Willigis Jäger, cuyas obras publicadas en España ha traducido la primera: Jäger, 1995; 1999; 2002; 2004; 2005; 2007; 2008). Incluso esta orientación del zen católico regenta una editorial, Zendo Betania, que dirige la maestra zen (en el pasado incluida entre las del Sambo Kyodan), religiosa católica y escritora Ana María Schlüter (1998; 2000; 2004; 2006; 2008a-b; 2009; 2011; 2014; 2016) y donde se ha publicado una obra de Koun Yamada (1993), líder de Sanbo Kyodan. Resulta destacado que fuese siguiendo este modo no budista de entenderlo como el primer zen cuya práctica se realizó de modo público en Espańa, se materializase. Y es que en 1976 el jesuita Hugo Enomiya-Lasalle, cuyos libros sobre el zen había publicado incluso con anterioridad la editorial católica Mensajero o también Herder y posteriormente ediciones Paulinas ${ }^{34}$, Sal Terrae y Zendo Betania (Enomiya, 1972; 1974; 1975; 1985; 1987; 1988; 1999; 2006ab), impartió un curso en la provincia de Madrid, un año antes de que se pusiese en marcha en Sevilla el primer centro budista zen. Pero como en el caso del zen que deriva de Karlfried Dürckheim, cuyas obras ha publicado principalmente Mensajero ${ }^{35}$, pero también Desclée de Brouwer (Dürckheim, 1977; 1982; 1984;

34 Donde también se han publicado libros de los padres jesuitas Ballester (1998), Kadowaki (1981) y el de Dunne (1978), todos ellos sobre budismo y cristianismo.

35 Ediciones Mensajero es la editorial católica que tiene un fondo de libros budistas más extenso, con obras, además de las antes citadas de Dürckheim, Castermane o del padre Enomiya-Lassalle (1972; 1974), del padre Dumoulin (1997; también 1982 en Herder), de Daisetz Teitaro Suzuki (1972; 1979a), de José Nalda (1984, en una biografía no inusual en 
1986; 1993; 1994; 1996a-b), y que han aparecido en traducción de su discípula Concha Quintana (que es traductora también de Jacques Castermane, 1989; 1997; 2010; 2016), lo que nos encontramos es con propuestas desbudistizadas, que además han solido ser acogidas en editoriales de clara orientación católica y en ningún caso han aparecido en las editoriales de orientación budista que hemos estado revisando en el apartado anterior.

Retomando la reflexión de futuro como conclusión, parece claro que los cambios tecnológicos están redefiniendo los modos de socialización del conocimiento en los grupos budistas. Resulta muy significativo que las revistas budistas de amplia difusión como Cuadernos de budismo o Dharma hayan dejado de publicarse, y que también se detecte una ralentización en la edición de libros budistas en los últimos años, en la que el peso de la crisis económica no puede llevarnos a minimizar otras razones menos coyunturales y que quizá preludien una pérdida de peso del libro, aún en sus nuevos formatos como e-books. Y es que muchas de las enseñanzas que resultan fundamentales entre los grupos budistas tienen una carga de oralidad que en el pasado era más difícil de socializar por dificultades meramente tecnológicas. Pero gracias a las posibilidades de generar productos multimedia y diseminarlos en la red en el presente resulta mucho más fácil y es de suponer que en el futuro lo será en aún mayor medida. Muchos de los libros repasados anteriormente, sobre todo los generados por editoriales budistas, eran enseñanzas orales que se vertían por escrito para poder diseminarlas. Ahora este esfuerzo no es tan necesario, el camino lo han desarrollado muchos grupos entre los que los seguidores de rigpa o los de Namkhai Norbu resultan ejemplares de cómo las enseñanzas de un maestro se pueden seguir en directo en todo el mundo y en diferido cuantas veces se desee por medio de las grabaciones que tan cómodo resulta actualmente realizar y utilizar gracias al enorme desarrollo de las tecnologías de información. Aunque de todos modos, esa oralidad tan unida al budismo desde siempre, que lleva a que sea lo escuchado el camino por el que los propios sermones de Buda se han ido recordando, no agota las posibilidades de producción de información. En una religión «de la biblioteca» como hemos planteado que es el budismo hay temas de reflexión para los que probablemente el libro siga siendo el canal más cómodo y adecuado y, por tanto, se siga manteniendo, en buena medida, como ese factor clave en la visibilización que es actualmente, que hemos analizado en este trabajo y que lleva a que resulte un producto editorial tan destacado a escala global y muy especialmente en nuestro país.

que la dedicación a las artes marciales japonesas derivan en un interés por el zen) o de Brantschen (2004). 


\section{Bibliografía}

Акоng (1993). El arte de domar el tigre. Novelda: Dharma.

- (2006). Recuperar el equilibrio, compartiendo la sabiduría tibetana. Valencia: Ediciones i.

Alongina, Xavier (1992). «Tormenta en el Instituto Dharma». Cuadernos de budismo Vol. 3, p. 16.

- (I996). «Entrevista con Gueshe Tamding Guiatso». Cuadernos de budismo Vol. 18, pp. 10-16.

— (1998). «Entrevista a Dokushô Villalba Osho, primer maestro budista zen español». Cuadernos de budismo Vol. 26, pp. 14-18.

- (I999). «18 años enseñando el darma en España. Entrevista al lama Lobsang Tsultrim». Cuadernos de budismo Vol. 30, pp. 6-10.

Antolín, Mariano / Embid, Alfredo (I977). Introducción al budismo zen. Barcelona: Barral.

Araque, Agustín (2008). El budismo. Su visión del ser humano y sus métodos de meditación. Valencia: Editorial Diálogo.

Arnau, Juan (2004). Fundamentos de la vía media de Nâgârjuna (traducción de Juan Arnau). Madrid: Siruela.

- (2006). Abandono de la discusión de Nâgârjuna (traducción de Juan Arnau). Madrid: Siruela.

- (2007). Antropología del budismo. Barcelona: Kairós.

- (20I I). Leyenda de Buda. Madrid: Alianza Editorial.

Arnold, Edwin (2008). La luz de Asia, Madrid, Miraguano (ed. or. 1879, traducción de José Javier Fuente del Pilar; hay traducciones previas, de la sociedad teosófica por Federico Climent Terrer).

Ballester, Mariano (1998). Cristo, el campesino y el buey, vía zen y vía cristiana. Madrid: Paulinas.

Batchelor, Stephen (2000). Solo con los demás, un acercamiento existencial al budismo. Ciutadella: Amara.

- (2008). Budismo sin creencias, una guía contemporánea para despertar. Móstoles: Gaia.

- (2012). Confesión de un ateo budista. Vitoria: La Llave.

- (2017). Después del budismo, repensar el dharma para un mundo secular. Barcelona: Kairós.

Beck, Charlotte Joko (2007). Zen ahora. Palma: Olañeta. 
- (2008). La vida tal como es, enseñanzas zen. Móstoles: Gaia.

- (2012). Zen, día a día, el comienzo, la práctica y la vida diaria. Móstoles: Gaia.

Blofeld, John (1979). El budismo tibetano. Barcelona: Martínez Roca.

- (1981). Mantras. Madrid: Edaf.

- (1982). La rueda de la vida, autobiografía de un budista occidental. Madrid: Eyras.

Bodнi, Bнiккu (2016). El Buddha Señala el Camino. El Noble Óctuple Sendero, el camino del Buddha al fin del sufrimiento. Madrid: Asociación Hispana de Buddhismo (traducción de Ricardo Guerrero).

BoKAR (1990). La meditación, consejos a los principiantes. Novelda: Dharma.

- (I995). Chenresi, la esencia de la compasión (coautoría con Kenpo Dönyö Rimpoché). Novelda: La auspiciosa roca blanca.

- (1997). El alba del Mahamudra, mente, meditación y absoluto. Novelda: Dharma.

- (1998). La iluminación del budismo, entrevistas con Bokar Rimpoché (por Paco Rabanne). Barcelona: Ediciones B.

- (2004a). El día a día de un budista. Graus: Chabsel.

- (2004b). Claves para meditar. Novelda: Dharma.

- (2004c). Tara, la manifestación femenina de la divinidad. Graus: Chabsel.

- (2005). Saber meditar. San Sebastián: Imagina.

- (2006). La puerta del sentido definitivo, instrucciones para la meditación. Graus: Chabsel.

- (2007). Chenresi, claves para la meditación en la divinidad. Graus: Chabsel.

- (2010). Un corazón sin límite. Graus: Chabsel.

- (2016). Puro e impuro, una mirada a los soles del Vajrayana. Graus: Chabsel.

Bouso, Raquel (2008). El zen (amb contrapunts de Ramon Badia, James W. Heisig, Berta Meneses). Barcelona: Fragmenta.

- (2012). El zen. Barcelona: Fragmenta.

Brantschen, Niklaus (2004). Por el camino del zen como cristiano budista. Bilbao: Mensajero.

Buddhadasa, Bhikku (2008). Lo que hay que saber del budismo. Ciutadella: Amara.

- (2012). Consejos de un sabio, el legado de Budaddhasa Bhikkhu. Ciutadella: Amara (traducción de Shanti Gordi).

Calle, Ramiro (1970). Introducción al zen y al lamaísmo. Barcelona: Cedel.

- (1980a). La genuina enseñanza del Buda. Buenos Aires: Kier.

- (1980b). Verdad y mentira de El Tercer Ojo. Madrid: Eyras.

- (I98I). El mensaje y enseñanza de los yoguis y lamas. Madrid: Altalena. 
- (1984). El budismo viviente. Barcelona: Cedel.

- (1988a). Introducción al Budismo Theravada. Barcelona: Alas.

- (1988b). Budismo zen y budismo tibetano. Barcelona: Alas.

- (1994). Buda. El principe de la luz. Madrid: Temas de hoy (nueva ed. Málaga: Sirio, 2006).

- (1998). Las enseñanzas de la meditación Vipassana. Barcelona: Kairós.

- (200I). Vida y Enseñanzas de Buda. Madrid: ed. Jaguar.

- (2004a). La sabiduría de los lamas tibetanos. Madrid: Susaeta.

- (2004b). Yoga y zen. Madrid: Oberon.

- (2005). Zen contado con sencillez. Madrid: Maeva ediciones.

- (2007a). Siddharta, el principe iluminado. Barcelona: Martínez Roca.

- (2007b). Buda y su enseñanza. Madrid: Edaf.

— (2009). La meditación budista. Málaga: Sirio.

- (201 I). Conversaciones con lamas y sabios budistas. Barcelona: Kairós.

- (2014). Meditación vipassana, el núcleo del mindfulness. Madrid: Librería Argentina.

Campillo, Joser Manuel (20 i ia). El secreto del zen, los textos esenciales legados por los patriarcas del budismo Soto Zen: Hannya Shingyo, Shinjinmei, Shodoka, Sandokai, Hokyo Zanmai, Fukanzazenji (edición, traducción y notas de Josep Manuel Campillo). Palma: Olańeta.

- (20 I Ib). Los diez bueyes y tres canciones zen, los versos que cantaron todos aquellos que buscaron la naturaleza de Buda (edición, traducción y notas de Josep Manuel Campillo). Palma: Olańeta.

- (20 I Ic). ¡Meditad! una respuesta espiritual a la crisis material actual. Palma: Olañeta.

Capriles, Elías (2000). Budismo y Dzogchen, la doctrina del Buda y el vehículo supremo del budismo tibetano. Vitoria: La Llave.

Castermane, Jacques (1989). Las lecciones de Dürckheim. Barcelona: Luciérnaga.

- (1997). El centro del ser (textos de Karlfried Graf Dürckheim reunidos por Jacques Castermane). Barcelona: Luciérnaga.

- (20 10). La alegría del ser. Bilbao: Mensajero (traducción de Concha Quintana).

- (2016). ¿Cómo se puede ser zen? Bilbao: Mensajero (traducción de Concha Quintana).

Castro, Aigo (2002). Las enseñanzas de Dogen. Barcelona: Kairós.

- (20 I I). "The Indian Buddhist Dhâranî. An Introduction to its History, Meanings and Functions». Trabajo fin de máster en Estudios Budistas, University of Sunderland (bajo la dirección de Peter Harvey). 
Снан, АJaнn (2005). Todo llega, todo pasa, enseñanzas sobre la cesación del sufrimiento. Barcelona: Oniro.

Champa Shenpen (2000). El sutra de la luz dorada (traducción de Champa Shenpen). Novelda: Dharma.

- (2017). Meditaciones para un año. Novelda: Dharma.

Chimed Rigdzin (2017). La aspiración radiante. Novelda: Dharma.

СнöDrön, Pema (1998). La sabiduría de la no-evasión, la senda del amor compasivo que lleva a la liberación. Barcelona: Oniro.

- (1999). Cuando todo se derrumba, palabras sabias para momentos difíciles. Móstoles: Gaia.

- (2002). Los lugares que te asustan, convertir el miedo en fortaleza en tiempos dificiles. Barcelona: Oniro (trad. catalana, Barcelona: Viena, 2005).

- (2004). Empieza donde estás, guía para vivir con compasión. San Sebastián: Imagina.

- (2012). No hay tiempo que perder. Sabiduría ancestral para los tiempos que corren. Madrid: Rigden.

- (2013a). Cómo meditar y ser al mismo tiempo un buen amigo de tu mente. Málaga: SiRIO.

- (2013b). Vivir bellamente en la incertidumbre y el cambio. Móstoles: Gaia.

- (2016). Comienza donde estás, una guía para vivir compasivamente. Móstoles: Gaia (nueva traducción de Chödron, 2004).

Сновdaк Yutнок (2003). El amanecer de la iluminación. Lamdre, serie de conferencias sobre las preciosas enseñanzas Lam Dre de la tradición Sakya del budismo tibetano. Ciutadella: Amara.

Снӧкүi Nyigma (2003). La guía del bardo, el ciclo de la vida y la muerte. Vitoria: La llave.

- (200I). Medicina y compasión, consejos de un lama tibetano para cuidadores. Móstoles: Gaia.

Chöpel, Karma Sönam (1995). Historia de Dag Shang Kagyu. Panillo: Ediciones Chabsel.

Colomar, Jorge (1974). El zen y sus orígenes. Barcelona: Martínez Roca.

Collado, José Manuel (2007). Mikkyo, budismo esotérico japonés. Barcelona: Shinden.

Coomaraswamy, Ananda K. (1989). Buddha y el Evangelio del Budismo. Barcelona: Paidós.

— (2000). Vida y leyendas de Buddha. Palma: Olañeta.

Crespo García, Ana (1997). El zen en el arte contemporáneo, la realidad y la mirada. Madrid: Mandala. 
Dagyap, Loden Sherab (I997). La esencia del budismo en la sociedad actual. Ciutadella: Amara.

- (2006). Concentración y contemplación, la meditación en la tradición tibetana. Novelda: Dharma.

Dalai Lama VII (20I3c). Nung ne, método para lograr el estado del Gran Compasivo de once caras (Avalokiteshvara) según la tradición de la bhikshuni Lakshmi con la práctica del ayuno y la súplica a los maestros del linaje. Madrid: Mahayana.

Dalai Lama XIV (1962). Mi vida y mi pueblo. La tragedia del Tíbet. Barcelona: Noguer.

- (I982a). Introducción al budismo tibetano. Madrid: Luis Cárcamo editor (traducción de Francisco F. Villalba).

- (I982b). Entrevista con el Dalai Lama por John F. Avedon. Monovar: Dharma.

- (1987). Una aportación humana a la paz mundial. Novelda: Dharma.

- (I 990a). Discurso del Dalai Lama ante el Comité Noruego del Premio Nobel. Novelda: Dharma.

- (I990b). Ciencia y espiritualidad, encuentros del Dalai Lama con cientificos actuales. Novelda: Dharma.

- (I994a). El tantra de Kalachakra, rito de iniciación para el estadio de generación. Novelda: Dharma.

- (I994b). Sobre el medio ambiente. Barcelona: Icaria (introducción de Raimon Panikkar).

- (I994C). La politica de la bondad, una antología de escritos del y sobre el Dalai Lama. Novelda: Dharma (ediciones posteriores, también en Barcelona: Círculo de Lectores).

- (I994d). La compasión y el individuo. Novelda: Dharma.

- (I995). El poder de la compasión. Barcelona: Martínez Roca.

- (I996a). Visión de una nueva consciencia. Ciutadella: Amara.

- (1996b). La búsqueda del despertar, comentario del Tercer Dalai Lama. Novelda: Dharma.

- (I997a). El sentido de la vida desde la perspectiva budista. Barcelona: Helios.

- (I997b). El buen corazón, una perspectiva budista de las enseñanzas de Jesús. Madrid: PPC.

- (1997c). El mundo del budismo tibetano, visión general de su filosofía y su práctica. Palma: Olañeta (ediciones posteriores también en Barcelona; Círculo de Lectores, RBA o Kairós).

- (I998a). CienciaMente, un diálogo entre Oriente y Occidente (coautoría con Daniel Goleman y Robert Thurman). Palma: Olañeta.

ÉNDOXA: Series Filosóficas, n. 42, 2018, pp. 69-136. UNED, Madrid 
- (I998b). Los beneficios del altruismo. Palma: Olañeta.

- (1998C). El sueño, los sueños y la muerte, exploración de la conciencia con S.S. el Dalai Lama. Palma: Olañeta.

- (1998d). El poder de la paciencia. Barcelona: Martínez Roca.

- (I998e). Samsara, la vida, la muerte y el renacer, el libro del Dalai Lama. Málaga: Sirio.

- (I998f). Sabiduría trascendental. Una enseñanza basada en el capitulo sobre la sabiduría de la obra Shantideva una guía a la forma de vida del Bodisatva. Novelda: Dharma.

- (1998g). Las cuatro nobles verdades. Barcelona: Plaza y Janés.

- (1999a). La fuerza del budismo. Barcelona: Ediciones B.

- (r999b). Conversaciones con El Dalai Lama. Ciutadella: Amara (ediciones posteriores, también Barcelona: Martínez Roca, 2005).

- (1999c). La sabiduría del Dalai Lama. Barcelona: Integral.

- (I999d). Como un relámpago ilumina la noche. Una guia al estilo de vida del Bodhisattva, comentario al El camino del Bodhisattva de Shantideva. San Sebastián: Imagina.

- (2000a). Océano de sabiduría, una guía para la vida. Barcelona: Oniro.

- (200ob). El arte de la felicidad. Barcelona: Grijalbo.

- (200 Ia). Más allá de los dogmas. Málaga: Sirio.

- (200 Ib). El camino del gozo, una guia práctica de las etapas de la meditación. Palma: Olańeta.

- (200Ic). Compasión y no violencia, reflexiones sobre la verdad, el amor y la felicidad. Barcelona: Kairós.

- (200Id). El arte de vivir en el nuevo milenio. Barcelona: Grijalbo.

- (200Ie). La meditación paso a paso. Barcelona: Grijalbo.

- (2002a). Consejos espirituales, un puente entre el budismo y Occidente. Barcelona: Oniro.

- (2002b). El ojo de la sabiduría y la historia del avance del Buddhadharma en el Tíbet. Barcelona: Kairós.

- (2003a). Acerca de la muerte. Barcelona: RBA.

- (2003b). El arte de la compasión. Barcelona: Debolsillo.

- (2003c). Joyas de la sabiduría del Tíbet. Novelda: Dharma.

- (2004a). El arte de la felicidad en el trabajo. Madrid: Kailas.

— (2004b). Consejos espirituales. Barcelona: Oniro. 
- (2004c). Pacificar la mente. Barcelona: Oniro.

- (2004d). Palabras de sabiduría. Palma: Olañeta.

- (2004e). El arte de la felicidad. Madrid: Kailas.

- (2004f). El corazón bondadoso, una visión budista de las enseñanzas de Jesús. Barcelona: Kairós.

- (2004g). Dzogchen. El camino de la gran perfección, enseñanzas dzogchen impartidas por Su Santidad el Dalai Lama. Barcelona: Kairós,

- (2004h). El sentido de la vida desde la perspectiva budista. Barcelona: Viena.

- (2004i). Loyong, adiestrar la mente. Novelda: Dharma.

- (2005a). El corazón de la sabiduría, las enseñanzas del Sutra del Corazón. Barcelona: Viena.

- (2005b). Un acercamiento a la mente lúcida. Novelda: Dharma.

- (2006a). El universo en un solo átomo. Barcelona: Grijalbo (Barcelona: Debolsillo, 2011).

- (2006b). La sabiduría del perdón, el camino de la comprensión y la tolerancia. Barcelona: Oniro.

- (2007a). La compasión y el individuo. La compassió $i$ la persona. Compassion and the individual. Barcelona: Fundació Casa del Tibet (edición previa en español en Dharma).

- (2007b). Los tres aspectos esenciales del camino. Valencia: Ediciones i.

- (2007c). Caminos hacia el nirvana. Barcelona: Kairós.

- (2007d). El arte de la sabiduría. Barcelona: Grijalbo.

- (2008a). La senda del líder. Empresa, budismo y felicidad en un mundo interrelacionado. Barcelona: Alienta.

- (2008b). La compasión universal. Barcelona: Paidós.

- (2008c). La mente en serenidad. Barcelona: Kairós.

- (2009a). Escritos esenciales. Maliaño: Sal Terrae.

- (2009b). Dormir, soñar y morir, una exploración de la consciencia con el Dalai Lama (edición de Francisco J. Varela). Móstoles: Gaia.

- (2009c). Sabiduría emocional. Barcelona: Kairós.

- (2010a). Mi biografía espiritual. Barcelona: Zenith.

- (2010b). Introducción al budismo tibetano. Barcelona: Paidós.

- (20 I Ia). Conócete a ti mismo tal como realmente eres. Barcelona: Debolsillo.

- (20 I Ib). Caminos de fe, cómo las religiones del mundo pueden convivir unidas. Barcelona: Zenith. 
- (2013a). El camino medio, la fe basada en el razonamiento. Barcelona: Rigden Institut Gestalt.

- (2013b). La mente despierta, cultivar la sabiduría en la vida cotidiana. Barcelona: Kairós.

- (2013c). El poder curativo de la meditación, diálogos científicos con el Dalai Lama. Barcelona: Kairós.

- (20 14). De aqui a la iluminación. Introducción al texto clásico de Tsong-kha-pa El gran tratado de los estadios en el camino a la iluminación. Barcelona: Kairós.

- (2015). Economía solidaria, conversaciones con el Dalai Lama sobre el altruismo y la compasión. Barcelona: Kairós.

- (2016a). El libro de la alegría, alcanza la felicidad duradera en un mundo en cambio constante. Barcelona: Grijalbo.

- (2016b). Más allá de la religión, ética para todo el mundo. Novelda: Dharma.

- (2016c). Budismo, un maestro, muchas tradiciones. Barcelona: Herder.

- (2016d). El corazón de la meditación. Barcelona: Martínez Roca (nueva ed. Barcelona: Booket, 2018).

David-Neel, Alexandra (1929). A través de la China misteriosa, viaje a pie de la China a la India, a través del Tíbet. Barcelona: Joaquín Gil editor.

- (1942). Misticos y magos del Tíbet. Madrid: Espasa Calpe (traducción de Rosa Spottorno de Ortega).

- (1978). El sortilegio del misterio. Barcelona: Edhasa.

— (1989). Viaje a Lhasa. Barcelona: Índigo.

- (1990). Inmortalidad y reencarnación. Madrid: Heptada.

- (2001). El budismo de Buda. Vitoria: La Llave.

- (2002). En el corazón del Himalaya, por los caminos de Katmandú. Palma: Olañeta.

Deshimaru, Taisen (1976). Za-zen, la práctica del zen. Viladrau, Gerona: Cedel.

- (1979). La práctica del Zen y cuatro textos canónicos Zen. Barcelona: Kairós.

- (I980). Zen y artes marciales. Madrid: Luís Cárcamo editor (traducción del francés de Taisei Dokushô -Francisco F. Villalba-).

- (198 Ia). El cuenco y el bastón, 120 cuentos zen. Barcelona: Visión libros (traducción española de Paco Villalba, revisada y corregida por Jorge A. Sánchez, director de la colección Visión zen); nueva edición, Barcelona: Edicomunicación, 1986 (traducción Francisco F. Villalba).

- (198 Ib). Canto del inmediato satori de Yoka Daishi. Barcelona: Visión libros, (traducción y comentarios de Taisen Deshimaru, traducción española de Paco Villalba). 
- (1982a). Autobiografía de un monje zen, Madrid. Luís Cárcamo editor (traducción del francés de Taisei Dokushô -Francisco F. Villalba-).

- (1982b). Preguntas a un maestro zen. Barcelona: Kairós (traducción de Francisco Fernández Villalba).

- (1982c). La práctica de la concentración. Barcelona: Teorema, colección Visión zen (traducción de Francisco Villalba; nueva edición, Barcelona: Edicomunicación, 1999).

- (1985). La voz del valle, enseñanzas zen. Barcelona: Paidós.

- (1986). Sutra y poemas zen. Madrid: Las mil y una ediciones/Asociación zen de España (edición a cargo de Francisco Dokushô Villalba).

- (1987a). Kannon Gyo, el sutra de la Gran Compasión. Madrid: Miraguano (comentarios de Taisen Deshimaru, traducción española de Dokushô Villalba).

- (1987b). Maha Prajna Paramita Sutra - Maka Hannya Haramita Shingyo, el sutra de la Gran Sabiduría. Madrid: Miraguano (comentarios de Taisen Deshimaru, traducción española de Dokushô Villalba).

- (1988). Shin jin mei, poema de la fe en el espiritu de Kanchi Sosan. Madrid: Miraguano (comentarios de Taisen Deshimaru, traducción española de Dokushô Villalba).

- (1989). L'anell de la via, paraules d'un mestre Zen. Lleida: Pagés.

- (1990). Zen y autocontrol (con Yujiro Ikemi). Barcelona: Kairós.

- (I99I). El zen de Dogen. Barcelona: Edicomunicación.

- (I992). El anillo de la vía. Barcelona: Ibis.

- (1994a). Zen y cerebro. Barcelona: Kairós.

- (I994b). La práctica del zen. Madrid: América Ibérica (ed. posteriores, Barcelona: RBA).

- (1995). La otra orilla, textos fundamentales de zen comentados por el maestro Taisen Deshimaru. Málaga: Sirio.

- (1995). Palabras Zen. Barcelona: Ediciones B.

- (2000). El blanco invisible (por Deshimaru y otros maestros). Valencia: Ahimsa.

- (200 ra). El canto del inmediato satori (traducido y comentado por Taisen Deshimaru). Barcelona: Kairós.

- (200 Ib). Zen verdadero, introducción al Shobogenzo. Barcelona: Kairós.

- (2003). La pràctica del zen. Barcelona: Publicacions de l'Abadia de Montserrat.

- (2005). Preguntes a un mestre zen. Lleida: Pagès.

- (2010). Autobiografia d'un monjo zen. Barcelona: Publicacions de l'Abadia de Montserrat.

— (201 I). El tesoro del zen, los textos fundamentales del maestro Dogen. Madrid: Oniro. 
Dhammasami, Khammai (2013). La meditación mindfulness. Madrid: Asociación Hispana de Buddhismo (traducción de Ricardo Guerrero).

Dhargey, Gueshe Tempa (1990). Lam Rim, el camino gradual a la iluminación. Novelda: Dharma.

Dhiravamsa (I99i). La vía del no apego. Barcelona: La Liebre de Marzo (múltiples ediciones).

- (1992). Retorno al origen. Barcelona: La Liebre de Marzo.

- (1997). La vía del despertar. Barcelona: La Liebre de Marzo.

- (200Ia). Palabras de sabiduría del Buda. Análisis psicoespiritual del comentario del Dhammapada. Vitoria: La Llave.

- (200 Ib). La leyenda de Shriton y Manorah o las pruebas del amor consciente. Vitoria: La Llave.

- (2004a). Una nueva visión del budismo, sintesis del alma oriental y del conocimiento occidental. Vitoria: La Llave.

- (2004b). El gran río de la Consciencia. Barcelona: La Liebre de Marzo.

- (2007). Meditación vipassana y eneagrama. Hacia un desarrollo humano y armonioso. Barcelona: La Liebre de Marzo (1ª ed. 1998).

- (2008a). Crisis y solución. Unión de opuestos. Barcelona: La Liebre de Marzo.

- (2008b). Meditación vipassana y gestalt (Dhiravamsa entrevistado por Juan José Díaz). Madrid: Mandala.

- (2009a). Un atajo a la Iluminación. Guía práctica de la atención plena. Vitoria: La Llave (con José Luis Molinuevo -Dharmapadipa-, nueva ed. 2013).

- (2009b). Iluminando la mente de cada eneatipo. Madrid: Mandala.

- (201 2a). Unión de los opuestos. Madrid: Mandala.

- (20 2 2b). La vía dinámica de la meditación, la liberación y la cura del dolor y el sufrimiento a través de las técnicas meditativas del vipassana. Barcelona: La Liebre de Marzo.

- (2014). Volviendo a la naturaleza primordial, cabalgando el buey de regreso a casa con euforia. Barcelona: La Liebre de Marzo.

- (2015). Los mudras de Buda. Barcelona: La Liebre de Marzo.

Díez de Velasco, Francisco (20 2). Religiones en España, historia y presente. Madrid: Akal.

- (2013). Budismo en España, historia, visibilización e implantación. Madrid: Akal.

- (2018). Budismo en España, historia, visibilización e implantación. Madrid: Akal, segunda edición (en formato e-book) puesta al día. 
Dilgo Kyentse (1994). Compasión intrépida, una explicación del Entrenamiento de la mente en siete puntos de Atisha. Novelda: Dharma.

— (1998a). Vivir, morir y vivir. San Sebastián: Imagina.

- (I998b). La meditación en la acción. San Sebastián: Imagina.

- (2005). El manantial de las realizaciones. La práctica del gurú yoga según la tradición de la esencia del corazón del vasto espacio. San Sebastián: Imagina.

- (2008). Los cien versos de consejos. Ciutadella; Amara.

- (20 I I). La esencia de la compasión. Novelda: Dharma.

Djinpa (2000). Introducción práctica al Buddhismo. Madrid: Editora Librería Argentina.

- (200I). Buddha, ciencia y espiritu. La convergencia de Oriente y Occidente. Madrid: Editora Librería Argentina (trad. catalana Aprenent del Budisme. Barcelona: Viena, 2007).

- (2002). Buddha, materialismo y muerte. El agujero negro de la globalización. Madrid: Editora Librería Argentina.

- (2009). Guía para el viaje de la muerte, compendio de enseñanzas sobre la impermanencia, los bardos y la muerte. Graus: Dag Shang Kagyu-Chabsel.

Dogen (1987). Shobogenzo zuimonki, enseñanzas Zen del maestro Eihei Dogen recopiladas por su sucesor Koun Ejo (prólogo y traducción al castellano de Dokusho Villalba). Madrid: Miraguano.

- (1989). Shushogi, principios de la práctica-iluminación en la vía del Buda (versión castellana y notas de Dokusho Villalba). Novelda: Dharma.

- (200I). Riqueza interior (traducción y comentarios por Dokusho Villalba del Fukanzazengi). Madrid: Miraguano.

- (2007). La Voz del valle, el color de las montañas (traducción y comentarios por Dokusho Villalba del capítulo Keisei Sanshoku, del Shobogenzo). Madrid: Miraguano.

- (2010a). Komyo, clara luz (traducción y comentarios por Dokusho Villalba del capítulo Komyo, del Shobogenzo). Madrid: Miraguano.

- (20Iob). Instrucciones al cocinero (edición, traducción y notas de Josep Manuel Campillo). Palma: Olañeta.

- (201 I). Hokyo-ki, diario de Dôgen en China (edición, traducción y prólogo de Dokushô Villalba). Madrid: Miraguano.

- (20I 2). El cuerpo real. Shobogenzo shinjin gakudo, estudiar la vía con el cuerpo y con la mente (traducción y comentarios de Dokushô Villalba). Madrid: Miraguano.

- (2013). Poesía mistica zen (edición, introducciones, comentarios y versión en castellano de los poemas de José M. Prieto). Madrid: Miraguano. 
- (20I4). El verdadero ojo de Buda, el Shobogenzo (edición de Josep Manuel Campillo). Palma: Olañeta.

- (20 I 5a). Ríos que retornan al océano (traducción y comentarios del Samadhi Sello Oceánico Shobogenzo Kaiin Zanmai por Dokushó Villalba). Madrid: Miraguano.

— (201 5b). Shobogenzo, la preciosa visión del Dharma verdadero (traducción anotada de Dokusho Villalba). Barcelona: Kairós.

Drubgyu Tenpa (2012). Madre liberadora. Graus: Chabsel.

DRUKPA XII (2000). La meditación del dragón. San Sebastián: Imagina.

- (201 5). La felicidad empieza en tu mente. Málaga: Sirio.

Dumoulin, Heinrichs (1982). Encuentro con el budismo. Barcelona: Herder.

- (1997). Para entender el budismo, temas clave. Bilbao: Mensajero.

- (2002). Zen, el camino de la iluminación en el budismo, orígenes y significado. Bilbao: Desclée de Brouwer.

Dunne, Carrin (1978). Buda y Jesús. Madrid: Paulinas.

Dürckheim, Karlfried (i 977$)$. El zen y nosotros. Bilbao: Mensajero.

- (1982). Meditar. ¿Por qué y cómo? Bilbao: Mensajero (versión española de Concha Quintana).

- (1984). El maestro interior, el maestro, el discípulo, el camino. Bilbao: Mensajero (versión española de Concha Quintana).

- (1986). Hara, centro vital del hombre. Bilbao: Mensajero (traducción de Concha Quintana).

- (1993). El despuntar del ser, etapas de maduración. Bilbao: Mensajero (versión espanola de Concha Quintana).

- (1994). Práctica del camino interior, lo cotidiano como ejercicio. Bilbao: Mensajero (versión española de Concha Quintana).

- (1996a). El sonido del silencio. Bilbao: Desclée de Brouwer (traducción de Concha Quintana).

- (1996b). El camino de la trascendencia. Bilbao: Mensajero (traducción de Concha Quintana).

Dzigar Kongtrül (2006). Depende de ti. Barcelona: Rigden Institut Gestalt.

- (2008). La luz que nos alcanza, enseñanzas budistas sobre el despertar de nuestra inteligencia natural. Barcelona: Rigden Institut Gestalt.

- (20 I 5). La felicidad que no se pierde, el camino del guerrero compasivo. Graus: Chabsel.

Enomiya-Lassalle, Hugo M. (1972). El zen. Bilbao: Mensajero.

- (1974). Zen, un camino hacia la propia identidad. Bilbao: Mensajero.

- (1975). El zen entre cristianos. Barcelona: Herder. 
- (1985). Zazen y los ejercicios de San Ignacio. Madrid: Paulinas.

- (1987). Vivir en la nueva conciencia, textos escogidos sobre cuestiones de nuestro tiempo. Madrid: Paulinas (traducción de Ana María Schlüter Rodés).

— (1988). Introducción al zazen. Brihuega: Editorial Zendo Betania (reeditado en 1992 y 1998).

- (I999). ¿A dónde va el hombre? Brihuega: Editorial Zendo Betania (antes en Santander, Sal Terrae 1982).

- (2006a). Zen y mistica cristiana. Brihuega: Editorial Zendo Betania (antes en Madrid: Paulinas, 1991, traducción de Ana María Schlüter Rodés).

- (2006b). La meditación, camino para la experiencia de Dios. Brihuega: Editorial Zendo Betania (antes en Santander: Sal Terrae 1981, traducción de Ana María Schlüter Rodés).

Faure, Bernard (201 2). Los tópicos del budismo. Barcelona: Kairós.

Fischer-Schreiber, Ingrid y otros (I993). Diccionario de la sabiduría oriental. Budismo, hinduismo, taoísmo, zen. Barcelona: Paidós.

Flores, Víctor Martínez (2008). Lo que debe saber el budista occidental. Madrid: Editora Librería Argentina.

Fraile, Miguel (1993). Meditación budista y psicoanálisis. Madrid: Edaf (2a ed. Madrid: Mandala, 2008).

- (2006). El grito silencioso, una valoración budista de la realidad. Madrid: Mandala.

Gampopa (2009). El precioso ornamento de la liberación. Graus: Chabsel.

García Ayuso, Francisco (I885). El nirvana buddhista en sus relaciones con otros sistemas filosóficos. Madrid: Tipografía de los Huérfanos.

Gira, Denis (2010). El budismo explicado a mis hijas. Barcelona: Paidós.

Glasenapp, Helmut von (1974). El budismo, una religión sin Dios. Barcelona: Barral (Valencia: Ahimsa, 2000).

Goldstein, Joseph (1995). La experiencia del conocimiento intuitivo, una guia sencilla $y$ directa para la meditación budista. Novelda: Dharma.

- (1996). Vipassana, el camino de la meditación interior. Barcelona: Kairós.

- (1998). La meditación vipásana, la práctica de la libertad. Novelda: Dharma.

- (2005). Un único dharma. El emergente budismo occidental. Barcelona: Libros de la Liebre de Marzo.

- (2009). Un corazón pleno de paz. Novelda: Dharma.

- (201 5). Mindfulness, una guía práctica para el despertar espiritual. Málaga: Sirio.

Goleman, Daniel (1997). La salud emocional. Conversaciones con el Dalai Lama sobre la salud, las emociones y la mente. Barcelona: Kairós. 
Gonsar (1994). La enseñanza de Buda, las cuatro nobles verdades. Ciutadella: Amara.

- (1996). La energía femenina del Tantra, Madre Tara. Ciutadella: Amara.

- (1999). La sabiduría budista, introducción a las cuatro escuelas filosóficas clásicas del budismo. Ciutadella: Amara.

GoRdi, IsIDro (1994). El arte de meditar. Ciutadella: Amara.

- (2004). Una guia para meditar, manual práctico de budismo tibetano. Ciutadella: Amara.

- (2007). La meditación, otra manera de afrontar tus problemas. Ciutadella: Amara.

- (2008). Ecos del silencio infinito, basado en comentarios clásicos y enseñanzas orales sobre el Sutra del corazón de la sabiduría. Ciutadella: Amara.

- (2009). El libro tibetano de la muerte. Ciutadella: Amara.

- (20 I Ia). El tantra de la diosa, tu ángel protector. Enseñanzas orales de Gueshe Tamding Gyatso. Ciutadella: Amara.

- (20 I Ib). Cambia tu corazón, transforma tu vida. Rayos de sol, comentario de Jorte Namka Pelsen al Adiestramiento de la mente en siete puntos de Gueshe Chekawa. Ciutadella: Amara.

- (2012). Enseñanzas de mi Lama, Gueshe Tamding Gyatso. Ciutadella: Amara.

- (2013a). Sé tu propio refugio, la serenidad de la meditación. Ciutadella: Amara.

- (2013b). Tu naturaleza interior, la mente y sus funciones, enseñanzas orales de Gueshe Tamding Gyatso. Ciutadella: Amara.

- (2016). Mindfulness y mucho más, el poder de la concentración. Ciutadella: Amara.

Govinda, Anagarika (1980). Fundamentos de la mistica tibetana. Madrid: Eyras.

- (I98 Ia). El camino de las nubes blancas, un peregrino budista en el Tíbet. Madrid: Eyras.

— (I98 Ib). El Libro tibetano de los muertos. Madrid: Edaf.

- (1992). Budismo vivo para Occidente, un texto que se considera exponente máximo de la nueva era. Madrid: Heptada.

- (200I). Peregrino del Himalaya. Valencia: Tres Joyas.

Grasdorff, Gilles van (2005). Panchen Lama, el niño elegido del Dalai Lama, rehén de Pekin. Un siglo de historia del Tíbet. San Sebastián: Imagina.

Gross, Rita (2005). El budismo después del patriarcado, historia, análisis y reconstrucción feminista del budismo. Madrid: Trotta.

Guendune (1997). Las emociones. San Sebastián: Imagina.

- (1999). Mahamudra, el gran sello o la vía del amor y la compasión. San Sebastián: Imagina.

Gunaratana, Henepola (2012). El libro del mindfulness. Barcelona: Kairós. 
- (2013). La meditación budista, el camino de la serenidad y la visión profunda. Barcelona: Kairós.

- (2015). Más allá del mindfulness, una guía introductoria a los estados más profundos de la meditación. Barcelona: Kairós.

- (2016). Meditación sobre la percepción, diez prácticas para cultivar la atención. Barcelona: Kairós.

- (2017). El cultivo del amor incondicional, la práctica de metta. Barcelona: Kairós.

Gyamtso, Khenpo Tsultrim (2006a). El sol de la sabiduría, enseñanzas sobre La sabiduría fundamental del camino medio de Nagarjuna. Novelda: Dharma.

- (2006b). Meditación progresiva sobre la vacuidad. Graus: Chabsel.

- (2006c). Distinguir los fenómenos y el ser auténtico de Maitreya con el comentario de Mipham (bajo las instrucciones de Khenpo Tsultrim Gyamtso Rinpoche). Graus: Chabsel.

- (2007). Charlas y canciones sobre las etapas progresivas de la meditación en la vacuidad. Madrid: Rigden.

- (2012). Estrellas de sabiduría, meditación analítica, canciones de júbilo del yogui y plegarias de aspiración. Graus: Chabsel.

Gyatso, Gueshe Tamding (1989). Las prácticas del bodhisattva. Ciutadella: Amara (traducción de Isidro Gordi).

- (I990). Senda de luz, comentario a la canción del Lam Rim de Je Tsong Khapa. Ciutadella: Amara (traducción de Isidro Gordi y Marta Moll).

- (I99I). El yoga del gurú, comentarios al yoga de las seis sesiones. Ciutadella: Amara (traducción de Isidro Gordi y Marta Moll).

- (1992). Más allá del egoísmo, comentario a la Rueda de las armas afiladas de Dharmarakshita. Ciutadella: Amara (traducción de Isidro Gordi y Marta Moll).

- (1993). Rayos de sol, comentario al texto de adiestramiento mental de Jorte Namka Pelsen. Ciutadella: Amara (traducción de Isidro Gordi y Marta Moll).

- (1994). Joyas del budismo. Ciutadella: Amara (traducción de Isidro Gordi y Marta Moll).

— (1995). La dama del espacio, comentario al Tantra de Vajra Yoguini. Ciutadella: Amara (traducción de Isidro Gordi y Marta Moll).

- (1997a). Tesoros de la meditación, un comentario al Bodhisatvacaryavatara, guía a la forma de vida del Bodhisatva de Shantideva. Ciutadella: Amara (traducción de Isidro Gordi y Marta Moll).

- (1997b). Muerte y reencarnación según el budismo tibetano. Ciutadella: Amara (traducción de Isidro Gordi y Marta Moll). 
(1997c). Senda de luz, comentario a la canción del Lam Rim de Lama Je Tsong Khapa. Ciutadella: Amara.

- (I998). Karma y renacimiento, según la lógica budista. Ciutadella: Amara (traducción de Isidro Gordi y Marta Moll).

- (2005). El descubrimiento de la suprema sabiduría de Buda, un comentario a El Sutra del corazón. Novelda: Dharma.

- (2013a). Cómo vencer tu ego, comentario al texto de Guru Darmarakshita Rueda de armas afiladas que golpea certeramente el punto vital del enemigo. Orense: Fundación Chu Sup Tsang.

- (2013b). El tesoro de la purificación, prácticas preliminares. Orense: Fundación Chu Sup Tsang.

- (2013c). Introducción al budismo. Orense: Fundación Chu Sup Tsang.

- (2014). Caminos de pureza. Orense: Fundación Chu Sup Tsang.

- (201 5 a). La experiencia de la muerte consciente. Novelda: Dharma.

- (201 5b). El lugar donde alcanzas la felicidad. Orense: Fundación Chu Sup Tsang.

- (20 I 5c). Autobiografía de una pequeña hormiga sobre la vasta tierra, la historia de un lama español nacido en el Tíbet. Orense: Fundación Chu Sup Tsang (han publicado edición también en tibetano).

HaAs, Michaela (2015). El poder de la Dakini, doce mujeres extraordinarias que modelan la transmisión del budismo tibetano a Occidente. Graus: Chabsel.

Hagen, STEve (2007). El budismo no es lo que crees, la verdadera naturaleza de las enseñanzas de Buda. Barcelona: Oniro.

Hayward, Jeremy (1998). Camino de Shambhala, el viaje sagrado hacia la liberación. Madrid: Gaia.

Heisig, James (2002). Filósofos de la nada, un ensayo sobre la Escuela de Kioto. Barcelona: Herder.

- (2007). El gemelo de Jesús, un alumbramiento al budismo. Barcelona: Herder.

Herrigel, Eugen (1980). El camino del Zen. Barcelona: Paidós.

Hui-Neng (1985). Vida y enseñanza de Huei-Neng sexto patriarca Zen. Madrid: Luis Cárcamo editor (traducción de Francisco F. Villalba).

Humphreys, Christmas (1985). Concentración y meditación, guia del desarrollo mental. Barcelona: Martínez Roca.

- (2005a). Zen, una forma de vida. Barcelona: Amat.

— (2005b). Budismo zen. Barcelona: Azul (edición anterior Buenos Aires 1962).

IKeda, DAisaku (1982). El Buda viviente. Barcelona: Gedisa.

— (1988). Budismo, primer milenio. Madrid: Taurus. 
- (1990). El misterio de la vida a la luz del budismo. Madrid: Heptada.

- (1996). Discursos de Daisaku Ikeda. Madrid: Soka Gakkai España.

- (1998). La sabiduría del sutra del loto, diálogo sobre la religión del siglo XXI. Madrid: Soka Gakkai España.

- (2003). La nueva revolución humana. Madrid: Soka Gakkai España.

- (2008a). Humanizar la religión y crear la paz. Propuesta de paz 2008. Madrid: Civilización Global.

- (2008b). Diálogo sobre la religión humanística. El mundo de los escritos de Nichiren Daishonin. Madrid: Civilización Global, 2 vols.

- (2009). Por la competencia humanitaria, una nueva corriente en la historia. Propuesta de paz 2009. Madrid: Civilización Global.

- (2010a). Por una nueva era de creación de valores. Propuesta de paz 2010. Madrid: Civilización Global.

- (20 Iob). El logro de la budeidad en esta existencia. Madrid: Civilización Global (ed. en catalán, 2014).

- (20 I I). Por un mundo de dignidad para todos, el triunfo de la vida creativa. Propuesta de paz 2011. Rivas: Civilización Global.

- (2012). Seguridad humana y sostenibilidad, el respeto universal a la dignidad de la vida. Propuesta de paz 2012. Rivas: Civilización Global.

- (2013). Amor compasivo, sabiduría y valentía, por una sociedad global de paz y de coexistencia creativa. Propuesta de paz 2013. Rivas: Civilización Global.

- (20I4). La creación de valor como factor de cambio global, construir sociedades sostenibles y resilientes. Propuesta de paz 2014. Rivas: Civilización Global.

- (201 5a). Un compromiso colectivo, erradicar el sufrimiento de la tierra y construir un futuro más humano. Propuesta de paz 2015. Rivas: Civilización Global.

- (201 5b). Develando los misterios del nacimiento y la muerte, sabiduría budista para la vida. Rivas: Civilización Global (ed. en catalán, 2017).

- (20 16a). El respeto universal a la dignidad humana, la gran vía hacia la paz. Propuesta de paz 2016. Rivas: Civilización Global.

- (2016b). La sabiduría del sutra del loto, diálogo con Daisaku Ikeda 1. Rivas: Civilización Global.

- (2017a). La solidaridad mundial entre los jóvenes augura una nueva era de esperanza. Propuesta de paz 2017. Rivas: Civilización Global.

- (2017b). La sabiduría del sutra del loto, diálogo con Daisaku Ikeda 2. Rivas: Civilización Global.

JäGER, Willigis (I995). En busca del sentido de la vida, el camino hacia la profundidad de nuestro ser. Madrid: Narcea (traducción de Carmen Monske). 
- (1999). En busca de la verdad, caminos-esperanzas-soluciones. Bilbao: Desclée de Brouwer (traducción de Carmen Monske).

- (2002). La ola es el mar, espiritualidad mistica. Bilbao: Desclée de Brouwer (traducción de Carmen Monske).

- (2004). Adonde nos lleva nuestro anhelo. La mistica en el siglo XXI, alocuciones, sermones, inspiraciones. Bilbao: Desclée de Brouwer (traducción de Carmen Monske).

- (2005). Partida hacia un país nuevo. Experiencias de una vida espiritual. Bilbao: Desclée de Brouwer (traducción de Carmen Monske).

- (2007). La vida no termina nunca. Sobre la irrupción en el ahora. Bilbao: Desclée de Brouwer (traducción de Carmen Monske).

- (2008). Sabiduría de Occidente y Oriente. Visiones de una espiritualidad integral. Bilbao: Desclée de Brouwer (traducción de Carmen Monske).

Jamgön Kongtrül (1997a). El canto al lama, texto raíz de la llamada al lama de lejos. San Sebastián: Imagina.

- (1997b). Cielo despejado, el camino del mahamudra de la escuela kagyu del budismo tibetano, comentario a la Doha Vajra. San Sebastián: Imagina.

- (1997c). La gran vía del despertar. Comentario de las enseñanzas Mahyana, los siete puntos del adiestramiento de la mente. San Sebastián: Imagina.

- (20 I4). La antorcha de la verdad, prácticas preliminares del Mahamudra. Barcelona: Fundación Rokpa.

- (2017). El jardín de la dicha. Breve comentario sobre la ofrenda del cuerpo. Graus: Chabsel.

Jampa Tegchok, Khensur (1994). Cómo transformar el pensamiento. Novelda: Dharma.

- (1995). Tras las huellas de los bodisatvas. Un comentario a las treinta y siete prácticas de los bodisatvas de Tokme Sangpo. Novelda: Dharma.

- (2016). Una mirada al vacio. Ciutadella: Amara.

Jigmé Norbou, Gyetrul (1997). Libertad a través de la meditación. San Sebastián: Imagina.

- (1998). Vivir libre. San Sebastián: Imagina.

- (2003). El sabor del dharma. Graus: Chabsel.

JinPa GyamTso (2006). Morir y volver a nacer, el ciclo continuo de la vida y de la muerte. Valencia: Ediciones i.

- (201 I). Una guia per a la mort. Tarragona: Aeditors.

KadowaKi, Johannes KaKichi (I98I). El zen y la Biblia, lectura corporal del koan y la Biblia, vivencia zen de un cristiano. Madrid: Paulinas. 
Kalu (2003). Fundamentos del budismo tibetano. Graus: Chabsel (hay otra ed. Barcelona: Kairós, 2005).

- (2006). Budismo vivo. Graus: Chabsel.

- (20 I Ia). Yoga interior del cuerpo, la palabra y la mente según la transmisión del gran yogui tibetano Kyabje Kalu Rinpoché. Graus: Chabsel.

- (20 I Ib). Budismo profundo. Graus: Chabsel.

- (2012). Budismo esotérico. Graus: Chabsel

Kapleau, Philip (198I). El despertar del zen de Occidente. Barcelona: Kairós.

- (1994). Los tres pilares del zen, enseñanza, práctica e iluminación. Madrid: Gaia.

- (1999). El zen de la vida y la muerte, guía práctica espiritual. Barcelona: Oniro.

KaYe, Les (200I). Las claves espirituales del éxito. Estrategias para el cambio y el éxito en la empresa a partir de la filosofía zen. Barcelona: RBA.

Kelsang Gyatso, Gueshe (1983). La esencia del budismo tibetano. Barcelona: Cymys, (traducción de Isidro Gordi).

- (1988). Corazón de la sabiduría, un comentario al Sutra del Corazón. Barcelona: Edicomunicación, (traducción de Mariana Líbano; $2^{a}$ ed. Cádiz: ediciones Tharpa, 2001).

- (1989). Luz clara del gozo. Mahamudra del budismo vajrayana. Ciutadella: Amara.

- (I99I). Compasión universal, comentario al Adiestramiento de la mente en siete puntos del bodhisatva Chekhaua. Barcelona: Ibis (traducción de Mariana Líbano, $2^{\text {a }}$ ed. Sevilla: Tharpa, 1996).

- (1992). Manual de meditación. Ciutadella: Amara (traducción de Mariana Líbano).

- (1993). Gema del corazón, la fuerza inspiradora del guía espiritual. Londres: Tharpa publications (traducción de Mariana Líbano).

- (1994). Introducción al budismo. Barcelona: ediciones Tharpa (traducción de Mariana Líbano).

- (I995a). El budismo en la tradición tibetana. Barcelona: Thassàlia (traducción de Miguel Martínez Lage).

- (I995b). Manual de meditación. Sevilla: ediciones Tharpa (traducción de Mariana Líbano).

- (1996a). Guia del paraíso de las Dakinis, la práctica del tantra del yoga supremo de Vajrayoguini. Sevilla: ediciones Tharpa (traducción de Mariana Líbano).

- (1996b). El camino gozoso de buena fortuna, el sendero budista hacia la iluminación. Sevilla: ediciones Tharpa (traducción de Mariana Líbano).

- (1998). Caminos y planos tántricos, cómo entrar en el camino vajrayana, recorrerlo y perfeccionarlo. Sevilla: ediciones Tharpa (traducción de Mariana Líbano). 
- (1999). Comprensión de la mente, naturaleza y funciones de la mente. Sevilla: ediciones Tharpa (traducción de Mariana Líbano).

- (200Ia). Introducción al budismo, una presentación del modo de vida budista. Cádiz: ediciones Tharpa (traducción de Mariana Líbano).

- (200Ib). Ocho pasos hacia la felicidad, el modo budista de amar. Cádiz: ediciones Tharpa (traducción de Mariana Líbano).

- (200Ic). Corazón de la sabiduría, las enseñanzas esenciales de Buda acerca de la sabiduria. Cádiz: ediciones Tharpa (traducción de Mariana Líbano).

- (2003). Tesoro de contemplación, el modo de vida del Bodhisatva. Cádiz: ediciones Tharpa (traducción de Mariana Líbano).

- (2004). Cómo solucionar nuestros problemas, las cuatro nobles verdades. Cádiz: ediciones Tharpa (traducción de Mariana Líbano).

- (2005). Una vida con significado, una muerte gozosa, la profunda práctica de la transferencia de consciencia. Cádiz: ediciones Tharpa (traducción de Mariana Líbano).

- (2006a). Gema del corazón, las prácticas esenciales del budismo kadampa. Málaga: ediciones Tharpa (traducción de Mariana Líbano).

- (2006b). Mahamudra del tantra, néctar de la gema suprema del corazón. Málaga: ediciones Tharpa (traducción de Mariana Líbano).

- (2007). Esencia del vajrayana, la práctica del tantra del yoga supremo del mandala corporal de Heruka. Málaga: ediciones Tharpa (traducción de Mariana Líbano).

- (2008). El voto del Bodhisatva, una guía práctica para ayudar a los demás. Málaga: ediciones Tharpa (traducción de Mariana Líbano).

- (2009). Transforma tu vida, un viaje gozoso. Málaga: ediciones Tharpa (traducción de Mariana Líbano).

- (2010). Compasión universal, inspiración para tiempos difíciles. Málaga: ediciones Tharpa (traducción de Mariana Líbano).

- (20 I Ia). Budismo moderno, el camino de la compasión y la sabiduría. Málaga: ediciones Tharpa (traducción de Mariana Líbano).

- (20 I Ib). Nuevo manual de meditación, meditaciones para una vida feliz y llena de significado. Málaga: ediciones Tharpa (traducción de Mariana Líbano).

- (2013a). Nuevo corazón de la sabiduría, enseñanzas profundas del corazón de Buda. Málaga: ediciones Tharpa (traducción de Mariana Líbano).

— (2013b). La vida de Buda. Málaga: ediciones Tharpa (traducción del Departamento de traducción de la editorial Tharpa).

- (2013c). ¿Qué es el budismo? Málaga: ediciones Tharpa (traducción del Departamento de traducción de la editorial Tharpa). 
- (2013d). La historia de Angulimala. Málaga: ediciones Tharpa (traducción del Departamento de traducción de la editorial Tharpa).

- (2013e). ¿Qué es la meditación? Málaga: ediciones Tharpa (traducción del Departamento de traducción de la editorial Tharpa).

- (20I4). Cómo comprender la mente, la naturaleza y el poder de la mente. Málaga: ediciones Tharpa (traducción del Departamento de traducción de la editorial Tharpa).

- (2016). Las instrucciones orales del Mahamudra, la esencia misma de las enseñanzas de Buda sobre el sutra y el tantra. Málaga: ediciones Tharpa (traducción del Departamento de traducción de la editorial Tharpa).

- (2017a). Nuevo ocho pasos hacia la felicidad, el modo budista de amar. Málaga: ediciones Tharpa (traducción del Departamento de traducción de la editorial Tharpa).

- (2017b). Cómo transformar tu vida, un viaje gozoso. Málaga: ediciones Tharpa (traducción del Departamento de traducción de la editorial Tharpa).

Kennedy, Robert (2008). Los dones del zen a la buisqueda cristiana. Bilbao: Desclée de Brouwer.

Khandro, Jetsun (2010). Esta preciosa vida, enseñanzas del budismo tibetano sobre el camino de la iluminación. Graus: Chabsel.

Kirimura, Yasuji (1990). Fundamentos de budismo. Madrid: Nichiren Shoshu Soka Gakkai de España.

Kosen, Bárbara (1999). Zen aqui y ahora. Enseñanza en el Mokusan Dojo con los comentarios del Bendowa. Madrid: Mandala.

- (2002). Zazenbuda, introducción al zazenshin del maestro Dogen. Madrid: Dilema.

KoRNFIELD, JACK (1997). Camino con el corazón, guia a través de los peligros y promesas de la vida espiritual. Barcelona: Los Libros de la Liebre de Marzo.

- (2000). Enseñanzas escogidas de Buda. Novelda: Dharma.

- (200I). Después del éxtasis, la colada. Barcelona: Los Libros de la Liebre de Marzo.

- (20 Iо). La sabiduría del corazón, una guía a las enseñanzas universales de la psicología budista. Barcelona: Los Libros de la Liebre de Marzo.

- (2013). Una lámpara en la oscuridad, iluminando el camino en tiempos difíciles. Móstoles: Gaia.

Kunsal Kassapa, Saya (20 I ia). Prodigios de los yoguis de Birmania, relato de una historia nunca antes revelada. Novelda: Dharma.

- (20 I Ib). Manual de introducción a la meditación. Madrid: Librería Argentina.

- (2012). Manual de introducción a la alquimia budista. Madrid: Librería Argentina.

LALOU, MarCelLe (1974). Las religiones del Tíbet. Barcelona: Barral.

Landaw, Jonathan (1990). El camino hacia la liberación. Novelda: Dharma. 
- (2009). Budismo para dummies. Barcelona: Granica (con ediciones posteriores).

Leadbeater, Charles (20 I I). Buda, vida y enseñanzas. Madrid: Librería Argentina.

Lenoir, Frédéric (2000). El budismo en Occidente. Barcelona: Barral (ed. or. París, 1999).

LlorCa, Basili (2009). Una guia de la mort per a budistes. Barcelona: Coordinadora Catalana d'Entitats Budistes.

Loori, John Daido (2002). El punto de quietud. Guía de meditación zen para principiantes. Madrid: Mandala.

Lopez, Donald (2009). El buddhismo. Barcelona: Kairós (traducción de Ferran Mestanza).

Low, Albert (1977). El zen y la dirección de empresas. Barcelona: Aura.

- (1994). Introducción a la práctica zen. Barcelona: Kairós.

- (2003). Conócete a ti mismo, relatos y enseñanzas zen. Madrid: Oberon.

Low, James (2010). Aqui y ahora. Un tesoro espiritual dsogchen de Nuden Dorje, el Espejo de significado claro. Novelda: Dharma.

- (2013a). Ser Guru Rimpoché, un comentario sobre la sadhana Guru Vidyadhara. Novelda: Dharma.

- (2013b). Dzogchen, enseñanzas y meditación budistas. Novelda: Dharma.

Loy, DAvid (2000). No dualidad. Barcelona: Kairós.

- (2004). El gran despertar, una teoría social budista. Barcelona: Kairós.

- (2008). Dinero, sexo, guerra y karma, ideas para una revolución buddhista. Barcelona: Kairós.

- (2016). Un nuevo sendero budista, la buisqueda de la iluminación en el mundo moderno. Barcelona: Kairós.

Lubac, Henri de (2006). Budismo y cristianismo. Salamanca: Sígueme (traducción de Xabier Picaza).

Mackenzie, Vicki (Tenzin Palmo) (i989). Reencarnación. El caso del niño lama. Madrid: Aguilar (trad. de la ed. inglesa de 1988).

- (1998). Maestros de la reencarnación, quiénes son, cómo fueron identificados, cómo transcurren sus vidas, cuál es su misión. Madrid: Neoperson.

- (2000). Una cueva en la nieve. La lucha por abrir las puertas del budismo a las mujeres, la buisqueda espiritual de Tenzin Palmo, Barcelona: RBA.

Maezumi, Hakuyu Taizan (2003). El valor de la vida, las enseñanzas del zen al alcance de todos. Barcelona: Oniro.

Manzanera, Juan (1998). El placer de meditar. Novelda: Dharma.

- (I999). La mirada del maestro. Barcelona: Martínez Roca (2a ed. Dharma, 2010). 
- (2003). El hallazgo de la serenidad, cuentos, reflexiones y meditación. Barcelona: Martínez Roca.

- (2010). La mirada del maestro. Novelda: Dharma (1ª ed. Martínez Roca, 1999).

- (20 I I). Meditación, la felicidad callada. Novelda: Dharma.

Mascaró, Juan (1982). El Dhammapada. La Sendera de la Perfecció (traducción de Juan Mascaró). Barcelona: Publicacions de l'Abadia de Montserrat.

Masià, Juan (1996). Buda y los budismos. Madrid: SM.

- (1997). Budistas y cristianos, más allá del diálogo. Maliaño: Sal Terrae.

- (1998). Aprender de Oriente, lo cotidiano, lo lento y lo callado. Bilbao: Desclée de Brouwer.

- (2003). El despertar de la fe, guía para ejercitarse en el budismo mahayana. Salamanca: Sígueme.

- (2006). El otro Oriente, más allá del diálogo. Maliaño: Sal Terrae.

- (2007a). El Dharma y el Espiritu, conversaciones entre un cristiano y un budista (con Kotaró Suzuki). Madrid: PPC.

- (2007b). Pararse a contemplar, manual de espiritualidad del budismo Tendai. Salamanca: Sígueme.

- (2009). El Sutra del Loto (traducción del J. Masià). Salamanca: Sígueme / Tokyo: Kosei Publishing.

Merton, Thomas (1972). El zen y los pájaros del deseo. Barcelona: Kairós.

- (2000). Diario de Asia. Madrid: Trotta.

- (2004). La experiencia interior. El encuentro del cristianismo con el budismo. Barcelona: Oniro.

Merzel, Dennis (2008). Gran Mente, Gran Corazón. Descubriendo tu propio camino. Barcelona: Libros de la Liebre de Marzo.

Mesa, Denkô (Francisco) (2005). Orígenes del budismo, vol. I de Budismo. Historia y Doctrina. Madrid: Miraguano.

- (2007). El Gran Vehiculo. Mahâyâna, vol. II de Budismo. Historia y Doctrina. Madrid: Miraguano.

- (2009). Zen. Entrega y confianza. Barcelona: Shinden ediciones.

- (2013). El viejo arte de darse cuenta. Enseñanzas del maestro Denko Mesa. Barcelona: Shinden.

- (2016). Zen, aroma eterno. Barcelona: Shinden.

Midal, Fabrice (2004). Trungpa. Biografia, el nacimiento del budismo occidental. Barcelona: MTM. 
Mínguez, Antonio (2006). "El maestro. Lobsang Tsultrim, 25 años en Espańa". Dharma Vol. 4, pp. 58-62.

Miyo (1993). El koan zen. Madrid: Mandala.

MontSerrat, Laia (20 I I). Un cerezo en el balcón, practicar zen en la ciudad. Barcelona: Kairós.

- (2017). La revolución del Hara, leibterapia y técnicas de centramiento. Barcelona: Kairós.

Moreno Lara, Xavier (1978). Zen, la conquista de la realidad. Barcelona: Barral.

- (1979). En el jardín del Zen. Bilbao: Comunicación Literaria de Autores.

Nagabodhi (1993). La meditación, el desarrollo de las emociones positivas. Valencia: Tres Joyas.

Nalda, JosÉ (1984). Iniciación al zen. Bilbao: Mensajero.

Namkhai Norbu, Chögyal (I996). El cristal y la vía de la luz, Sutra, Tantra y Dzogchen. Barcelona: Kairós.

- (1997). El yoga de los sueños y la práctica de la luz natural. Novelda: Dharma (traducción de Xavi Alongina).

- (2002). Dzogchen, el estado de autoperfección. Vitoria: La Llave.

- (2007). Enseñanzas Dzogchen. Barcelona: Los Libros de la Liebre de Marzo.

- (2008). Tantra de la fuente suprema. Barcelona: Kairós.

- (20 I). Nacimiento, vida y muerte, según la medicina tibetana y la enseñanza dzogchen. Barcelona: Kairós.

- (2015). Yoga tibetano del movimiento, el arte y la práctica del Yantra Yoga. Barcelona: Kairós.

- (2017). El fundamento del dharma, una aproximación al dzogchen. Barcelona: Kairós.

Nandisena, Bhikku (20I2). Dhammapada (traducción de Bhikku Nandisena). Madrid: Asociación Hispana de Buddhismo.

Narada Thera (2008). Vida después de la vida según el budismo. Madrid: Editora Librería Argentina.

- (2016). Buddhismo en pocas palabras. Madrid: Asociación Hispana de Buddhismo. (traducción de Ricardo Guerrero).

Nhat Hahn, Thich (1978). Claves del zen. Salamanca: Sígueme.

- (I993a). Momento presente, momento maravilloso. Novelda: Dharma.

— (1993b). El sol, mi corazón. Novelda: Dharma.

- (1996a). Buda viviente, Cristo viviente. Barcelona: Kairós.

- (1996b). El florecer del loto, ejercicios de meditación para la transformación interior. Madrid: Edaf. 
- (1999). Transformación y sanación, el Sutra de los cuatro fundamentos de la conciencia. Barcelona: Paidós.

- (2000). Vivir el budismo o la práctica de la atención plena. Barcelona: Kairós.

- (2001). Volviendo a casa, el camino común de Buda y Jesús. Barcelona: Oniro.

- (2002). Las enseñanzas del Buda, los tres sutras fundamentales. Barcelona: Oniro.

- (2003). La muerte es una ilusión, la superación definitiva del miedo a morir. Barcelona: Oniro.

- (2005). Lograr el milagro de estar atento. Un manual de meditación. Madrid: Editora Librería Argentina.

- (2007). Camino viejo, nubes blancas, tras las huellas del Buda. Novelda: Dharma.

- (2009). Las enseñanzas de Buda. Barcelona: Oniro.

- (2010). La mente y el cuerpo del Buda. Barcelona: Oniro.

- (20 I I). Estás aqui, descubriendo la magia del momento presente. Barcelona: Kairós.

- (2013a). Miedo, vivir en el presente para superar nuestros temores. Barcelona: Kairós.

- (2013b). Felicidad, prácticas esenciales de plena consciencia. Barcelona: Kairós.

- (2014a). ¿Por qué existe el mundo?, preguntas infantiles y respuestas zen sobre la vida, la muerte, la familia y todo lo demás. Barcelona: Kairós.

- (2014b). El milagro de mindfulness. Barcelona: Oniro.

- (2016). Silencio, el poder de la quietud en un mundo ruidoso. Barcelona: Urano.

- (2017a). Comprender nuestra mente. Barcelona: Kairós.

— (2017b). El arte de cuidar a tu niño interior. Barcelona: Paidós.

- (2018a). Sintiendo la paz. Barcelona; Zenith (1ª ed. Barcelona: Oniro, 1999).

- (2018b). El corazón de las enseñanzas de Buda. Barcelona: Zenith. (1ª ed. Barcelona: Oniro, 1999).

- (20 I 8c). La esencia del amor. Barcelona: Zenith (1ª ed. Barcelona: Oniro, 1999).

Nichiren (2008). Los escritos de Nichiren Daishonin (supervisión e introducción de Carlos Rubio). Barcelona: Herder / Madrid: Soka Gakkai.

- (2013). Liturgia del budismo de Nichiren Daishonin. Rivas: Civilización Global.

Nishida, Kitaro (2006). Pensar desde la nada. Salamanca: Sígueme.

Nishitani, Keiji (1999). La religión y la nada. Madrid: Siruela.

Niwano, Nikkyo (2013). Budismo para el mundo de hoy, interpretación actualizada del tríptico de los Sutras del Loto. Salamanca: Sígueme.

Nyanaponika Thera (1982). El corazón de la meditación budista. Madrid: Eyras.

- (2002). Grandes discipulos de Buda, su vida, sus actividades, su legado. Novelda: Dharma. 
- (2005). El camino de la atención, el corazón de la meditación budista. Madrid: Editora Librería Argentina.

- (2006). La liberación del error, las raíces del bien y del mal. Madrid: Editora Librería Argentina.

- (2007a). El poder de la atención. Madrid: Editora Librería Argentina (edición anterior, Gerona: Cedel, 1980).

- (2007b). Los fundamentos de la atención. Madrid: Editora Librería Argentina.

- (20 I4a). La ciudad de la mente, el camino de la calma y el bienestar. Madrid: Editora Librería Argentina.

- (2014b). Meditación = Mindfulness, sobre las sensaciones. Madrid: Editora Librería Argentina.

Nyanatiloka (1984). La paraula del Buda. Compendi de liensenyament del Buda compost amb textos seleccionats de les escriptures budistes originals en llengua pâli. Barcelona: Publicacions de liAbadia de Montserrat.

Nydahl, Ole (1989). Cuando el pájaro de hierro vuele. Tres años con los buddhas del techo del mundo. San Sebastián: Karmapa.

Olcott, Henry S. (1923). Catecismo buddhista. Barcelona: Biblioteca Orientalista (nueva edición, Madrid: Editora Librería Argentina, 2010).

Pabongka (2016). El tantra del gozo. Vajrayoguini. Ciutadella: Amara.

Palden, Tsering (2016). Vagando por el samsara, el libro de las transiciones. Madrid: Delam.

Palden, Kunzang (2015). La ambrosía de las palabras de Mañyusri. Un comentario detallado de la práctica del bodisatva de Shantideva. Novelda: Dharma.

Pallis, Marco (1986). Espectro luminoso del budismo. Barcelona: Herder.

Palma, Daniel de, trad. (1998). Diálogos con Buddha, 12 suttas del Majjhima Nikâya. Madrid: Miraguano.

Panchen Lama I (2017). Senda hacia la serenidad. Mahamudra. Ciutadella: Amara.

PanikKar, Raimon (1996). El silencio del Buddha. Una introducción al ateismo religioso. Madrid: Siruela.

Paramananda (2010). Cambia tu mente, una guia práctica a la meditación budista. Valencia: Tres Joyas.

Patrul (I999). El tesoro del corazón de los iluminados, la práctica de la visión, la meditación y la acción. San Sebastián: Imagina.

Pauling, Chris (1993). Iniciación al budismo. Valencia: Tres Joyas.

Piyadassi Thera (2008). Meditación budista. Vipassanâ. Madrid: Editora Librería Argentina. 
Preciado, Iñaki (i 994). Vida de Milarepa (traducción de I. Preciado). Barcelona: Anagrama.

- (I998). Treinta consejos de Gyalwa Lochenpa (traducción de I. Preciado). San Sebastián: Imagina.

- (2000). Joyas de la sublime vía (traducción de I. Preciado). San Sebastián: Imagina.

- (200 Ia). En el país de las nieves, viajes por los laberintos tibetanos. Barcelona: Martínez Roca.

- (200 Ib). Canciones liricas del sexto Dalai Lama. Madrid: Hiperion.

- (2003). Svástika, religión y magia del Tíbet. Madrid: Oberon.

— (2004). El sembrador de oro y otros cuentos del Tíbet. Madrid: Oberon.

- (2013). Adiós, Tíbet, adios, la agonía del pueblo tibetano. Madrid: Miraguano.

- (2015). Bon, la sabiduría mágica del Tíbet. Madrid: Miraguano.

Prieto, José María (20 i I). El sutra de la eternidad dorada, budismo y catolicismo en Jack Kerouac. Madrid: Miraguano.

Pujol, Oriol (2003). ¿Qué hace Buda en mi empresa?, sabiduría budista en las organizaciones de hoy. Barcelona: Granica.

RAmírez, LAUREANO, TRAD. (2002). Sutra de Vimalakirti. Barcelona: Kairós.

Rech, Yuno (Roland) (200o). Monje zen en Occidente, conversaciones con Romana y Bruno Solt. Lleida: Milenio.

- (2004). Zen o el despertar en la vida diaria. Lleida: Milenio.

- (2016). La realización del despertar, las enseñanzas del maestro Dogen. Lleida: Milenio.

Redondo, Rafael (2005). La radicalidad del zen. Bilbao: Desclée de Brouwer.

- (2008). Zen, la experiencia del ser. Bilbao: Desclée de Brouwer.

- (2010). El esplendor de la nada. Bilbao: Desclée de Brouwer.

- (2015). Ser la propia luz. Más allá de linajes y maestros, de escuelas y creencias. Bilbao: Desclée de Brouwer

Ricard, MatThieu (i998). El monje y el filósofo. Barcelona: Urano (en coautoría con Jean François Revel).

- (200I). El infinito en la palma de la mano, del Big Bang al despertar. Barcelona: Urano.

- (2005). En defensa de la felicidad. Barcelona: Urano.

- (2009). El arte de la meditación, ¿por qué meditar?, ¿sobre qué?, ¿cómo?. Barcelona: Urano.

- (2016). En defensa del altruismo, el poder de la bondad. Barcelona: Urano. 
Riggs, Nicole (2005). Como una ilusión, las vidas de los maestros shangpa kagyu. Graus: Chabsel.

Ringu Tulku (2001). La meditación budista. Bruselas: Bodhicharya.

- (2002). El budisme explicat als occidentals. Barcelona: Viena (trad. al castellano Barcelona: Viena, 2002, 2a ed. 2012 en ediciones Invisibles).

- (2012). Adiestrar la mente, enseñanzas del lo jong. Barcelona: editorial P. Forn.

- (2014). De la llet al iogurt, una guia per a la vida i la mort. Barcelona: Viena

Roach, Michael (200I). El tallador del diamante, el Buda y sus estrategias para dirigir tus negocios y tu vida. Ciutadella: Amara (traducción de Isidro Gordi y Marta Moll).

- (2003a). La magia de los maestros vacios, un retiro en silencio. Ciutadella: Amara (traducción de Isidro Gordi).

- (2003b). El libro tibetano del yoga. Ciutadella: Amara (traducción de Isidro Gordi y Marta Moll).

- (2008). La enseñanza de Jesús en el Tibet. Ciutadella: Amara (traducción de Isidro Gordi y Marta Moll).

- (20I I). Gestiona tu karma, recoges lo que siembras, tanto en los negocios como en la vida. Ciutadella: Amara (traducción de Carlos Ossés).

Rodríguez de Peñaranda, Miguel (2012). El budismo, una perspectiva histórico-filosófica. Barcelona: Kairós.

Román, María Teresa (1994). "Análisis del problema de la conciencia en el Prajñaparamita Hridaya sutra”. Tesis doctoral leída en la UNED.

- (1997). Buda, sendero del alma. Madrid: UNED.

- (2002). Diccionario antológico de budismo. Madrid: Alderabán.

- (2004). Sabidurias orientales de la Antigüedad. Madrid: Alianza.

- (2007). Un viaje al corazón del budismo. Madrid: Alianza.

Rosenberg, Larry (2005). Aliento tras aliento, la práctica liberadora de la meditación vipassana. San Sebastián: Imagina.

SAHn, SeUng (199I). Tirando cenizas sobre el Buda, las enseñanzas del maestro zen Seung Sahn. Barcelona: Los Libros de la Liebre de Marzo.

- (1998). Cartas de un maestro de zen. Novelda: Dharma.

- (2002). La brújula del zen. Barcelona: Los Libros de la Liebre de Marzo.

- (20 Io). Diálogos para la serenidad, enseñanzas del maestro zen Seung Sahn. Barcelona: Oniro.

Sakya Tashi Ling, Lama Blanco (2006). El camino del héroe. Barcelona: Martínez Roca. 
Sakya Tashi Ling, Monjes budistas (2007). Manual de cocina para la felicidad. Madrid: Aguilar.

— (2008). Live peace. Olivella, Barcelona: Sakya Tashi Ling.

Sakya Trizin (2012). Libera tu Corazón y tu Mente. Ciutadella: Amara.

Sakyong Mipham (2003). Convertir la mente en nuestra aliada. Editorial Descleé: Bilbao.

- (2007). Gobierna tu vida. Estrategias ancestrales para la vida moderna. Barcelona: Oniro.

- (2015). Correr y meditar, enseñanzas para entrenar el cuerpo y la mente. Vitoria: La Llave.

- (2016). El principio de Shambhala, descubriendo el tesoro oculto de la humanidad. Vitoria: La Llave.

SaLAs, Lluis (20 I6). Ensenyances a Lluçà 1, ensenyança oral de Lluís Nansen Salas donada en els retirs Zen de Lluçà i Barcelona, 2012-2013. Barcelona: Dojo Zen Barcelona Kannon.

- (2017a). Ensenyances zen a Lluçà 2, ensenyança oral de Lluís Nansen Salas donada en els retirs zen de Lluçà i Barcelona, 2014-2015. Barcelona: Dojo Zen Barcelona Kannon.

- (2017b). Meditació Zen. Lsart de simplement ser. Barcelona: Edicions Viena, 2017.

- (2017c). Meditación Zen. El arte de simplemente ser. Ediciones Invisibles: Barcelona.

San José Garcés, Pedro (2009). Charlas de un aprendiz de zen. Madrid: Mandala.

- (2010). Desde ¿quién soy yo? a ¿qué hacer?, un diálogo laico siguiendo a Siddharta Gautama y a Jesús de Nazaret. Madrid: Mandala.

Sangharakshita (1993a). El budismo, la enseñanza y su práctica. Valencia: Tres Joyas.

- (1993b). El budismo en Occidente. Valencia: Tres Joyas.

- (I994a). La iluminación, el ideal del desarrollo humano, un encuentro con los ideales y los métodos del budismo. Valencia: Tres Joyas.

— (1994b). ¿Quién es el Buda? Valencia: Tres Joyas.

- (1994c). Sólo existe el momento presente, la mente y la conciencia. Valencia: Tres Joyas.

- (1997). Los Diez Pilares del budismo. La base de la filosofía y la ética orientales. Barcelona: Oniro.

- (I999). Introducción al budismo tibetano, la más misteriosa rama de la espiritualidad oriental. Barcelona: Oniro.

- (200I). Budismo. Introducción a la filosofia, la meditación y la práctica de la tradición budista. Barcelona: Oniro. 
- (2008). Una panorámica del budismo, su doctrina y sus métodos a lo largo de la historia. Novelda: Dharma.

- (201 Ia). El camino del arco iris, memorias de un monje budista inglés, fundador de la Orden Budista Triratna. Valencia: Triratna.

- (20 I Ib). El diálogo del Buda sobre el amor incondicional, vivir con bondad, el Sutta Karaniya Metta. Valencia: Triratna.

- (20 I Ic). La sangha. Valencia: Triratna.

- (2012). Conoce tu mente, explorando la dimensión psicológica en la ética budista a través de los textos canónicos del abhidharma. Valencia: Triratna.

SaWaki, Kodo (2012). El Zen es la mayor patraña de todos los tiempos. Casas del Río, Valencia: Comunidad Budista Soto Zen (prólogo y edición anotada de Dokushô Villalba. Traducción de Javier Fernández Retenaga).

SAYADAw, Mahasi (2008). Meditación vipassana paso a paso. Madrid: Editora Librería Argentina.

Schlüter Rodés, Ana María (1998). Mistica oriental y mística cristiana. XXII Foro sobre el Hecho Religioso (coeditora con José Ignacio González Faus). Maliaño: Sal Terrae / Madrid: Fe y Secularidad.

- (2000). Biografias de maestros zen. Brihuega: Editorial Zendo Betania.

- (2004). Guía del caminante. Brihuega: Editorial Zendo Betania.

- (2006). La palabra desde el silencio. Brihuega: Editorial Zendo Betania.

- (2008a). El verdadero vacio, la maravilla de las cosas. Brihuega: Editorial Zendo Betania.

— (2008b). "Bilingüismo religioso" en Javier Melloni, ed., El no-lugar del encuentro religioso. Madrid: Trotta, pp. 155-168.

- (2009). Atrévete con el dragón vivo, el arte del zazen. Brihuega: Editorial Zendo Betania.

- (2011). Recepción del zen en occidente entre cristianos: reflexiones en el camino. Brihuega: Editorial Zendo Betania.

- (2014). Cantos rodados, mi camino hacia el zen. Madrid: PPC.

- (2016). Zendo Betania. Donde convergen zen y fe cristiana. Bilbao: Desclée de Brouwer.

Schneider, David (2007). El zen de la calle, la vida y obra de Issan Dorsey. Valencia: Ediciones i.

Senghe, Gueshe Jampel (1984). Sueños, muerte y bardo. Novelda: Dharma (traducción de Xavi Alongina).

Sengue, Cheuky (2007a). El templo tibetano y su simbolismo. Graus; Chabsel. 
- (2007b). Pequeño léxico de budismo tibetano. Graus; Chabsel.

Shantideva (1995). Destellos de sabiduria, el Bodhisatvacaryavatara de Shantideva. Ciutadella: Amara.

- (2004). Guía de las obras del Bodhisatva, cómo disfrutar de una vida altruista y llena de significado. Cádiz: Tharpa.

- (2009). El bodhicharyavatara. Introducción a la práctica del Bodhisattva. Graus: Chabsel.

- (2013). La vida del bodisatva. Bodhisattvacharyavatara delñ Acharya Shantideva. Programa básico de la FPMT. Madrid: Mahayana (traducción de Jesús Revert y Nerea Basurto para el servicio de Traducción de la FPMT).

Shi Dayuan (2015). Sintonizando la voz del Chan. Madrid: Asociación Hispana de Buddhismo.

Simmer-Brown, Judith (2002). El cálido aliento de la dakini, el principio femenino en el budismo tibetano. Barcelona: MTM.

Sinnett, Alfred P. (1902). El budismo esotérico. Madrid: Editorial Rodríguez Sierra (nueva edición, Madrid: Editora Librería Argentina, 2011).

SMEDT, Evelyn DE (1997). Zen y cristianismo; la enseñanza del maestro Deshimaru. Lleida: Milenio.

Soepa, Thubten (2011). Enseñanzas budistas en torno al vegetarianismo. Novelda; Dharma.

SogYal (1994). El libro tibetano de la vida y de la muerte. Barcelona: Urano (con múltiples ediciones posteriores).

- (1996a). Destellos de sabiduría, reflexiones sobre la vida y la muerte. Barcelona: Urano.

- (1996b). Meditación. Palma: Olañeta.

- (2004). El futuro del budismo. Barcelona: Urano.

- (201 I). El llibre tibetà de la vida i de la mort. Sabadell: Dipankara.

Solé-Leris, Amadeo (Asoka Dhammaviriya) (i986). La meditación budista. Barcelona: Martínez Roca (nueva ed. 1995, trad. inglesa Boston: Shambala 1986; trad. italiana Milano: Mondadori, 1988; trad. alemana Freiburg: Herder, 1994).

Solé-Leris, Amadeo y Vélez de Cea, Abraham, trads. (1999). Majjhima Nikãya. Los sermones medios del Buddha. Barcelona: Kairós.

Song y otros (1989). Visiones del dharma, enseñanzas de los lamas tibetanos. Novelda: Dharma (traducciones de Anila Jampa Chokyi y Xavi Alongina).

Sumano, Ajahn (2012). Una mente brillante, una introducción a la meditación budista. Barcelona: Oniro.

SuvajRa (1994). La vida de Dhardo Rimpoche, un lama tibetano. Valencia: Tres Joyas. 
Suzuki, Daisetz Teitaro (1972). La gran liberación. Bilbao: Mensajero.

- (1979a). Introducción al budismo zen. Bilbao: Mensajero.

- (I979b). Budismo zen y psicoanálisis. Madrid-México: FCE.

- (1981). El ámbito del zen. Barcelona: Kairós.

- (1994). Vivir el zen, historia y práctica del budismo zen. Barcelona: Kairós.

- (1996). El zen y la cultura japonesa. Barcelona: Paidós.

- (2001). El Buda de la luz infinita, las enseñanzas del budismo Shin. Barcelona: Paidós.

- (2006). ¿Qué es el zen? Madrid: Losada.

Suzuki, Shunryu (2003). No siempre será así. El camino de la transformación personal. Barcelona: Oniro.

- (2004). Corrientes que fluyen en la oscuridad. El Sandokai a la luz del budismo zen. Barcelona: Oniro.

- (2012). Mente Zen, mente de principiante, charlas informales sobre la meditación y la práctica del Zen. Madrid: Gaia.

Tai Situ (1983a). Perlas del Dharma, colección de enseñanzas de sus eminencias Tai Situ Rinpoché y Gyaltsab Rinpoché y del muy venerable Kalu Rinpoché. Barcelona: Asociación Dagpo.

- (1983b). Comentario sobre Los siete puntos de la práctica mental, de Atisha. Barcelona: Asociación Dagpo (traducción de Ángel Vidal).

- (I983c). Cánticos del Mahamudra. Barcelona: Asociación Dagpo.

- (1994). Los siete puntos de la práctica mental. Barcelona: Obelisco (traducción de Jimpa Gyamtso).

- (2007). Adiestramiento mental en siete puntos. Valencia: Ediciones i.

- (2017). Ya somos perfectos. Novelda: Dharma.

Tarthang Tulku (2001). El cultivo de la conciencia en el trabajo. Vitoria: La Llave.

- (2002). Enseñanzas del corazón. Vitoria: La Llave.

- (2003). Mente sobre materia, reflexiones sobre el budismo en Occidente. Vitoria: La Llave.

- (2010). Conocimiento de la libertad, es hora de cambiar. Barcelona: Urano.

Tashi Tsering, Gueshe (2003). Memorias de un tibetano. Madrid: Amaranto.

- (2006). Las cuatro verdades nobles de Buda. Ciutadella: Amara.

- (2007). Estudio de la mente, psicología budista. Ciutadella: Amara.

- (2009). Nada es lo que parece, verdad relativa y verdad absoluta en el budismo tibetano. Ciutadella: Amara.

- (2010). El gran vacio, fundamentos del pensamiento budista. Ciutadella: Amara. 
- (2012). La mente del despertar, el poder del amor. Ciutadella: Amara.

- (2016). Tantra. Ciutadella: Amara.

Tendzin, Ösel (2004). Buda en la palma de la mano. San Sebastián: Imagina.

Tenzing TAmding (2008). Vida, enfermedad y muerte. Sevilla: Los Libros de Unzaloa.

- (2010). El sendero de la realización mahayana, programa de estudios budistas, curso 2009. Valencia: Fundación Chu Sup Tsang.

- (2011). El sendero de la realización mahayana, programa de estudios budistas, curso 2010. Valencia: Fundación Chu Sup Tsang.

- (2012a). El sendero de la realización mahayana, programa de estudios budistas curso 2011. Orense: Fundación Chu Sup Tsang.

- (20 I 2b). Puerta a la sabiduría, comentario a la sadana breve de Manyushri. Orense: Fundación Chu Sup Tsang.

- (2012c). Transformar la adversidad, comentario a Los ocho versos de adiestramiento mental de Gueshe Lang ri Dham pa. Orense: Fundación Chu Sup Tsang.

- (2013a). El sendero de la realización Mahayana, programa de estudios budistas curso 2012. Orense: Fundación Chu Sup Tsang.

- (2013b). Caminos de pureza. Orense: Fundación Chu Sup Tsang.

- (2013c). El tesoro de la purificación, prácticas preliminares. Orense: Fundación Chu Sup Tsang.

- (2014A). El sendero de la realización Mahayana, programa de estudios y prácticas del budismo mahayama curso 2013. Orense: Fundación Chu Sup Tsang.

- (20 I 4b). El mapa de la existencia. Orense: Fundación Chu Sup Tsang (también edición en inglés).

— (20I4c). La felicidad. Orense: Fundación Chu Sup Tsang (también edición en inglés y en alemán).

- (20 I4d). Luz clara de la lámpara que cambia la dirección de tu vida. Orense: Fundación Chu Sup Tsang.

- (2015a). El sendero de la realización mahayana, programa de estudios y prácticas del budismo mahayana curso 2014. Orense: Fundación Chu Sup Tsang.

- (20 I 5b). Por el proceso de morir se convierte en tres cuerpos de Buda. Orense: Fundación Chu Sup Tsang.

- (2015c). Fuente de toda virtud, enseñanzas sobre el camino gradual de la felicidad. Orense: Fundación Chu Sup Tsang.

- (2015d). Libro de recitaciones. Orense: Fundación Chu Sup Tsang.

- (2016a). El sendero de la realización mahayana, programa de estudios y prácticas del budismo mahayana: curso 2015. Orense: Fundación Chu Sup Tsang. 
- (20 I6b). Mente y salud. Enseñanzas en el Centro de estudios budistas Ganden Choeling de Menorca los días 8, 9, 10, 11 y 12 de julio de 2009. Orense: Fundación Chu Sup Tsang.

- (2016c). Fuente de toda virtud, enseñanzas sobre el camino gradual de la felicidad 2. Retiro Lam Rim 2015. Orense: Fundación Chu Sup Tsang.

- (2016d). El ladrón de tu felicidad vive contigo. Orense: Fundación Chu Sup Tsang.

- (2017a). El sendero de la realización mahayana, programa de estudios y prácticas del budismo mahayana: curso 2016. Orense: Fundación Chu Sup Tsang.

- (2017b). Comentario del Fundamento de toda excelencia. Orense: Fundación Chu Sup Tsang.

- (2017c). Puya de fuego. Orense: Fundación Chu Sup Tsang.

- (2017d). Fuente de toda virtud, enseñanzas sobre el camino gradual de la felicidad 3. Retiro Lam Rim 2016. Orense: Fundación Chu Sup Tsang.

Thaye, Jampa (2009). Lluvia de claridad, etapas del camino a la iluminación en la tradición Sakya. Ciutadella:Amara (traducción de Shanti Gordi).

Thondup Tulku (2010). Las enseñanzas escondidas del Tíbet, una exposición de la tradición, terma del budismo tibetano. Sabadell: Dipankara.

Thrangu (1983). El camino de la liberación, comentario a la plegaria del Mahamudra Dorje Chang Thungma. Barcelona: Samye Dzong.

- (2014). Señalando el dharmakaya, enseñanzas basadas en el texto homónimo del IX Karmapa. Graus: Chabsel.

Thubten Chodron (1989). Los factores mentales. Novelda: Dharma.

- (1993). Corazón abierto, mente lúcida. Novelda: Dharma.

- (2002). Budismo para principiantes. Madrid: Alianza.

- (2012). El camino a la felicidad. Novelda: Dharma.

Thurman, Robert (1994). El libro tibetano de los muertos. Barcelona: Kairós.

- (1995). El budismo tibetano esencial. Barcelona: Robin Book.

- (2000). La revolución interior, la vida, la libertad y la búsqueda de la verdadera felicidad. Barcelona: Urano.

- (2006). Ira. Barcelona: Paidós.

- (2012). La vida infinita, el despertar de la consciencia en una sociedad terminal. Vitoria: La llave.

- (2014). Amad a vuestros enemigos, cómo acabar con el hábito de la ira y ser más felices. Barcelona: Kairós.

Tola, Fernando / Dragonetti, Carmen, trads. (2000). El sutra de los infinitos significados. Bilbao: Desclée de Brouwer. 
- (2002). Dhammapada. Barcelona: RBA.

- (2006). Udana, la palabra de Buda. Madrid: Trotta.

- (2010). Diálogos mayores de Buda, Digha Nikaya. Madrid: Trotta.

Torralba, Francesc / Wangmo, Jamyang (2002). Carta sobre Dios y Buda. Un laico cristiano dialoga con una monja budista. Lleida: Editorial Milenio.

Torres Crespo, María (1994). Sobre la cola del cometa Osel. Memorias de la madre de un lama reencarnado. Barcelona: Plaza y Janes.

Traleg Kyagbon (2015). Antigua sabiduría tiempos modernos, una introducción a la filosofía y práctica del budismo. Ciutadella: Amara.

Triet, Raphael Doko (2002). Unsui. Sevilla: Seikyuji (nuevas eds. en 2005, 2009, 2011).

Trinle Dorje, Ogyen (2008). El libro del Monlam Kagyu, una compilación para la recitación. Barcelona: Fundación Rokpa.

- (20 I 2). Un ngondro para nuestro tiempo, una práctica corta del ngondro con instrucciones. Barcelona: Kagyu Samye Dzong Barcelona, Fundación Rokpa.

- (2013). El corazón es noble, cómo cambiar el mundo desde dentro hacia fuera. Málaga: Sirio.

- (2014a). El libro del Monlam Kagyu, una compilación para la recitación. Barcelona/ Bodhgaya, India: Kagyu Monlam International.

- (20I4b). Música en el cielo, vida, obra y enseñanzas del XVII Gyalwa Karmapa Ogyen Trinle Dorje (por Michele Martin). Novelda: Dharma.

- (2017). Interconectados, abrirnos a la vida en la sociedad global. Barcelona: Kairós.

Tritul Nyare (2009). Serenidad mental, la práctica tibetana de meditación shiné. Novelda: Dharma.

- (2016). Lamtso nam sum, los tres aspectos principales del camino. Orense: Chu Sup Tsang.

- (2017). Comentario del Mandala. El gran océano de Mérito. Orense: Chu Sup Tsang.

Trungpa, Chögyam (1976). El amanecer del Tantra (con Herbert Guenther). Barcelona: Kairós.

- (1985). Más allá del materialismo espiritual. Barcelona: Edhasa.

- (1986). Shambhala, la senda sagrada del guerrero. Barcelona: Kairós.

- (1989). Abhidharma, psicología budista. Barcelona: Kairós.

- (1991а). Dharma, arte y percepción visual. Barcelona: MTM.

- (I99ib). El corazón de Buda. Barcelona: MTM (traducción de Montse Castellà).

- (I993). Meditación en la acción. Madrid: Edaf (nueva ed. Kairós, 2012; trad. al catalán, Barcelona: Viena, 2002). 
- (1995). Loca sabiduría. Barcelona: Kairós.

- (I998a). El mito de la libertad y el camino de la meditación. Barcelona: Kairós.

- (1998b). El camino es la meta. Barcelona: Oniro.

- (200I). El corazón de Buda. Barcelona: MTM (traducción de Montse Castellà).

- (2002). El sol del gran este, la sabiduría de Shambhala. Barcelona: Kairós.

- (2003a). Nacido en Tíbet. Novelda: Dharma (traducción de Xavi Alongina).

- (2003b). Enseñanzas esenciales de Chögyam Trungpa, Vitoria: La Llave.

- (2007). Nuestra salud innata, un enfoque budista de la psicología. Barcelona: Kairós.

- (2009). El libro tibetano de los muertos, la gran liberación a través de la escucha en el bardo. Madrid: Gaia (con Francesca Fremantle).

- (2010). La verdad del sufrimiento y el camino de la liberación. Barcelona: Kairós.

- (20 I I). Sonrie al miedo, despierta tu valentía interior. Barcelona: Kairós.

- (2016). Mindfulness en acción: guía para la conciencia plena a través de la meditación. Barcelona: Kairós.

Tsang Nyon Heruka (201 2a). Vida de Marpa el traductor. Novelda: Dharma.

- (2012b). La vida de Milarepa, el gran yogui del Tíbet. Barcelona: Dipankara.

Tsongkapa (1998). Fundamentos del tantra, una montaña de bendiciones. Ciutadella: Amara (traducción de Isidro Gordi y Marta Moll).

Tsultrim, Gueshe Lobsang (1988). La Perfección de la paciencia. Novelda: Dharma (traducción de Mercedes Pérez-Albert y Valentín Mencía).

- (I991a). Vida y enseñanzas de un lama tibetano. Novelda: Dharma (traducción de Encarna López Pastor).

- (199r). El adiestramiento mental y los doce vínculos de originación interdependiente. Novelda: Dharma (traducción de Xavi Alongina).

- (I999). La doble trampa del apego y el rechazo. Novelda: Dharma (traducción de Encarna López Pastor. Edición en catalán, 2004).

- (200I). Instrucciones de Atisha y los Gueshes Kadampas, Tibet, año 1000. Novelda: Dharma (traducción de Encarna López Pastor).

- (20 I I). Sobre la felicidad. Novelda: Dharma (traducción de Encarna López Pastor).

Tucci, Giuseppe (1973). Teoria y práctica del mandala. Barcelona: Barral.

- (20 I 2). Las religiones del Tíbet. Barcelona: Paidós.

Ueda, Shizuteru (2004). Zen y filosofía. Barcelona: Herder (edición a cargo de Raquel Bouso García). 
Vega, Amador (2002). Zen, mistica y abstracción, ensayos sobre el nibilismo religioso, Madrid: Trotta (ed. or. Passió, meditació i contemplació. Sis assaigs sobre el nibilisme religiós. Barcelona: Editorial Empúries).

Vélez de Cea, Авraham (1997). Buddha. Madrid: Ediciones del Orto.

- (2000). El buddhismo. Madrid: Ediciones del Orto.

- (2003). Nagarjuna. Versos sobre los fundamentos del Camino Medio (traducción de A. Vélez). Barcelona: Kairós.

Villalba, Dokusho (1984). ¿Quées el Zen? Madrid: Miraguano (4ª ed. 2017, traducida al portugués en 2014).

- (1995). Psicoterapia y Espiritualidad (coautor con Xavier Serrano). Valencia: Ediciones Orgón.

- (1997). De corazón a corazón, enseñanza oral del maestro Zen Dokushô Villalba. Casas del Río, Valencia: Comunidad Budista Soto Zen.

- (1998). Vida simple, corazón profundo. Madrid: Miraguano.

- (1999). Fluyendo en el presente eterno. Madrid: Miraguano.

- (2000). Siempre ahora. Madrid: Miraguano.

- (2005). La experiencia de la muerte. Valencia: producciones Alalba (6 cds).

- (2008). Zen en la plaza del mercado. Madrid: Aguilar (nueva ed. Kairós, 2016, traducción al rumano 2009).

- (2009). Zen (Dhyana - Chan - Seon). vol. III de Budismo, Historia y Doctrina. Madrid: Miraguano.

- (2010). Iluminación silenciosa, antología de textos soto zen. Madrid: Miraguano.

Wangmo, Jamyang (2009). El lama de Lawudo. Madrid: editorial Kailas (Lawudo Lama: Stories of Reincarnation from the Mount Everest Region. Boston: Wisdom Publications, 2003).

Wangyal, Tenzin (2013a). El despertar de la mente luminosa, meditación tibetana para la alegría y la paz de interior. Móstoles: Gaia.

- (201 3 b). El despertar del cuerpo sagrado, yogas tibetanos de la respiración y el movimiento. Móstoles: Gaia.

- (2017). La verdadera fuente de sanación, la antigua práctica tibetana de la recuperación del alma. Móstoles: Gaia.

Watts, Alan (1971). El camino del zen. Barcelona: Edhasa (eds. posteriores, 1975, 1977, 1984, 2002, 2003, 2006).

- (1996). Hablando de zen, charlas y escritos de Alan Watts. Málaga: Sirio.

- (I999). Budismo, la religión de la no-religión. Barcelona: Kairós. 
Webb, Russell (1998). "Budismo en España e Iberoamérica", en Peter Harvey, El budismo. Madrid: Cambridge University Press, pp. 362-380.

Western Shugden Society (20 Io). La gran falacia. La política de los lamas gobernantes. Málaga: Western Shugden Society-Tharpa.

WetTering, JANWILlem VAN DE (I976). Reflejos en la nada, experiencias en una comunidad Zen de Estados Unidos. Barcelona: Kairós.

- (1984). El espejo vacío, experiencias en un monasterio zen. Barcelona: Kairós.

- (2000). Afterzen, experiencias de un estudiante zen de patitas en la calle. Barcelona: Libros de la Liebre de Marzo.

Wetzel, Sylvia (2002). Mujer y budismo en Occidente. Barcelona: Icaria.

Wilber, Ken (2016). El cuarto giro, evolucionando hacia un budismo integral. Barcelona: Kairós.

Yamada, Koun (1993). Barrera sin puerta con comentarios del mestro Zen Kôun Yamada. Brihuega: Zendo-Betania (traducción de Ana María Schlüter).

Yamahata, Hôgen (2005). Hojas que caen, un brote que surge. Ahora, un perfecto milagro. Barcelona: MTM.

YeSHe Losal (2006). Vivir el camino: un método práctico de meditación budista para la vida cotidiana. Valencia: Ediciones i.

Yeshe, ThubTen (1988a). Enseñanzas sobre Tara. Novelda: Dharma (traducción de Xavi Alongina).

- (1988b). Introducción al Tantra. Novelda: Dharma (traducción de Basili Llorca).

- (1989). La realidad humana. Novelda: Dharma (traducción de Montse Castellà).

- (1993). Tara, la energía femenina que libera. Novelda: Dharma (traducción de Xavi Alongina).

- (I995). Introducción al Tantra, una visión de la totalidad. Novelda: Dharma (traducción de Basili Llorca).

- (1996). El camino tántrico de la purificación, el método de yoga de Heruka Vajrasatva. Novelda: Dharma (traducción de Mercedes Pérez Albert).

- (2000). El gozo de la meditación avanzada, la práctica de los seis yogas de Naropa. Novelda: Dharma (traducción de Mercedes Pérez Albert).

- (200I). Sé tu propio terapeuta, una introducción al pensamiento budista. Novelda: Dharma (traducción de Mercedes Pérez Albert).

- (2003). Tu mente es un océano, aspectos de la psicología budista. Novelda: Dharma (traducción de Mercedes Pérez Albert).

- (2005). Claridad y vacuidad, el tantra de Avalokitesvara. Novelda: Dharma (traducción de Xavi Alongina). 
- (2008). Ego, apego y liberación, aprende a superar tu burocracia mental, un curso de meditación de cinco días. Novelda: Dharma (traducción de Xavi Alongina y Eduardo García Arévalo).

- (2009). La esencia del budismo tibetano. Novelda: Dharma (traducción del equipo del Servicio de Traducción de la FPMT Hispana).

- (2013). Cuando ya no queda chocolate. Novelda: Dharma (traducción de Eduardo García-Arévalo).

- (20I4). La mente silenciosa, budismo, mente y meditación. Novelda: Dharma (traducción de Xavi Alongina).

- (2016). Libertad por el conocimiento, el camino budista a la felicidad y a la liberación. Novelda: Dharma (traducción de Tenzin Guelek).

Yeshe, Thubten y Zopa, Thubten (199i). La energía de la sabiduría. Novelda: Dharma (traducción de Anila Jampa Chokyi, edición previa Madrid, Arión, 1979).

- (2013). La práctica de Vajrasattva, prácticas preliminares. Madrid: Mahayana (traducción de Nicolás Viñés).

Yongey Mingyur (2008). La alegría de la vida, descubra el secreto y la ciencia de la felicidad. Barcelona: Granica.

- (2010). La dicha de la sabiduria, abrazar el cambio y encontrar la libertad. Barcelona: Rigden Institut Gestalt.

- (2012). La alegría de vivir, el secreto y la ciencia de la felicidad. Barcelona: Rigden Institut Gestalt.

- (2016). Transformar la confusión en claridad. Barcelona: Kairós.

Yuan, Fan TA SHI (2012). Conferencias de budismo chan. Orense: Chu Sup Tsang.

Zhang, Zenji (20 I I). La práctica del zen, Introducción a la antigua tradición del budismo chian. Sabadell: Dipankara.

Zopa, Thubten (1989). La felicidad y el sufrimiento. Novelda: Dharma (traducción de Xavi Alongina).

- (1994). Transformar problemas en felicidad. Novelda: Dharma (traducción de Mercedes Pérez Albert).

- (1995). La puerta de la satisfacción, el consejo esencial de un maestro del budismo tibetano. Novelda: Dharma (traducción de Mercedes Pérez Albert).

- (1999). Virtud y realidad, método y sabiduría en la práctica del darma. Novelda: Dharma (traducción de Mercedes Pérez Albert).

- (200I). Budismo y contemplación para cada día. Novelda: Dharma (recopilación y traducción de Juan Manzanera).

- (2009). Curación definitiva, el poder de la compasión. Novelda: Dharma (traducción de Enrique Iranzo y Mercè Blasco). 
- (2010). Dar sentido a la vida. Novelda: Dharma (traducción del departamento de traducción de Ediciones Dharma).

— (20 I I). Cómo ser feliz. Novelda: Dharma (traducción de Eduardo García Arévalo).

- (20 I2a). Miedo saludable, transformar tu angustia por la transitoriedad y la muerte. Novelda: Dharma (traducción de Javier Agenjo).

- (20 I 2b). Prácticas esenciales para el momento de la muerte. Madrid: Mahayana (traducción del servicio de Traducción de la FPMT).

- (20 I 2c). Consejos esenciales para el momento de la muerte. Madrid: Mahayana (traducción del servicio de Traducción de la FPMT).

- (2013a). Postraciones a los 35 budas de la confesión, prácticas preliminares. Madrid: Mahayana (traducción de Nicolás Viñés).

— (2013b). Preparación del altar y ofrecimiento de agua, prácticas preliminares. Madrid: Mahayana (traducción de Joan Dombón y Rafael Ferrer).

- (20 I 3c). El corazón del camino, ver al Buda en el maestro. Novelda: Dharma (traducción de Mercedes Pérez Albert).

- (2014a). Ofrecimiento del mandala. Novelda: Dharma (recopilación de Juan Vidal).

- (20 I 4b). Consejos esenciales para el retiro (con Pabongkha Dechen Ningpo). Madrid: Mahayana (traducción del servicio de Traducción de la FPMT).

— (2015). Tu mente crea tu realidad. Novelda: Dharma (traducción de Alejandra Alma$\mathrm{da})$.

- (2016). Cómo practicar el dharma, las ocho preocupaciones mundanas. Novelda: Dharma (traducción de Mercedes Pérez Albert).

Zubieta, Miguel Ángel (200I). La meditación y la transformación de la mente. Valencia: Tres Joyas.

Enviado: $17 / 03 / 2018$

Recibido: 23/10/2018

Este trabajo se encuentra bajo una licencia de Creative Commons ReconocimientoNoComercial-SinObraDerivada 4.0

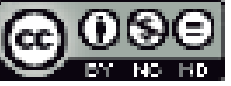

